\title{
REGULATION OF GLUTATHIONE SYNTHESIS
}

\author{
Shelly C. Lu, M.D.* \\ Division of Gastroenterology and Liver Diseases, USC Research Center for Liver Diseases, USC- \\ UCLA Research Center for Alcoholic Liver and Pancreatic Diseases, Keck School of Medicine USC, \\ Los Angeles, California 90033
}

\begin{abstract}
Glutathione (GSH) is a ubiquitous intracellular peptide with diverse functions that include detoxification, antioxidant defense, maintenance of thiol status, and modulation of cell proliferation. GSH is synthesized in the cytosol of all mammalian cells in a tightly regulated manner. The major determinants of GSH synthesis are the availability of cysteine, the sulfur amino acid precursor, and the activity of the rate-limiting enzyme, glutamate cysteine ligase (GCL). GCL is composed for a catalytic (GCLC) and modifier (GCLM) subunit and they are regulated at multiple levels and at times differentially. The second enzyme of GSH synthesis, GSH synthase (GS) is also regulated in a coordinated manner as GCL subunits and its up-regulation can further enhance the capacity of the cell to synthesize GSH. Oxidative stress is well known to induce the expression of GSH synthetic enzymes. Key transcription factors identified thus far include Nrf2/Nrf1 via the antioxidant response element (ARE), activator protein-1 (AP-1) and nuclear factor $\kappa$ B (NFאB). Dysregulation of GSH synthesis is increasingly being recognized as contributing to the pathogenesis of many pathological conditions. These include diabetes mellitus, pulmonary fibrosis, cholestatic liver injury, endotoxemia and drug-resistant tumor cells. Manipulation of the GSH synthetic capacity is an important target in the treatment of many of these disorders.
\end{abstract}

\section{Keywords}

Glutathione; glutamate cysteine ligase; GSH synthase

\section{Structure and Functions of GSH}

Glutathione is a tripeptide, $\gamma$-L-glutamyl-L-cysteinyl-glycine, found in all mammalian tissues and especially highly concentrated in the liver. Glutathione exists in the thiol-reduced (GSH) and disulfide-oxidized (GSSG) forms (Kaplowitz et al., 1985). GSH is the predominant form, existing in millimolar concentrations in most cells (liver 5-10mM). The GSSG content is less than $1 \%$ of GSH (Akerboom et al., 1982). Eucaryotic cells have three major reservoirs of GSH. Almost $90 \%$ of cellular GSH are in the cytosol, $10 \%$ is in the mitochondria and a small percentage is in the endoplasmic reticulum (Meredith and Reed, 1982; Hwang et al., 1992). Cytosolic GSH in the rat liver turns over rapidly with a half-life of $2-3$ hours. The peptide bond linking glutamate and cysteine of GSH is through the $\gamma$-carboxyl group of glutamate rather than the conventional $\alpha$-carboxyl group (Fig. 1). This unusual arrangement is subject to

\footnotetext{
*To whom correspondence should be sent: HMR Rm 415, Department of Medicine, Keck School of Medicine USC, 2011 Zonal Ave. Los Angeles, CA 90033, Tel: (323) 442-2441, FAX: (323) 442-3234, e-mail: E-mail: shellylu@ usc.edu.

Publisher's Disclaimer: This is a PDF file of an unedited manuscript that has been accepted for publication. As a service to our customers we are providing this early version of the manuscript. The manuscript will undergo copyediting, typesetting, and review of the resulting proof before it is published in its final citable form. Please note that during the production process errors may be discovered which could affect the content, and all legal disclaimers that apply to the journal pertain.
} 
hydrolysis by only one known enzyme, namely $\gamma$-glutamyltranspeptidase (GGT), which is only present on the external surfaces of certain cell types (Meister and Anderson, 1983). As a consequence, GSH is resistant to intracelluar degradation and is only metabolized extracellularly by organs with GGT.

GSH serves several vital functions including 1) detoxifying electrophiles; 2) scavenging free radicals; 3 ) maintaining the essential thiol status of proteins; 4) providing a reservoir for cysteine; and 5) modulating critical cellular processes such as DNA synthesis, microtubularrelated processes, and immune function (Kaplowitz et al., 1985; Meister and Anderson, 1983; DeLeve and Kaplowitz, 1990; Suthanthiran et al., 1990). In addition, GSH has been shown to regulate nitric oxide homeostasis (Hogg, 2002), modulate the activity of proteins by post-translational modification (protein S-glutathionylation) (Pompella et al., 2003), and modulate the activity of neurotransmitter receptors (Oja et al., 2000). Clearly GSH is a multifunctional molecule with diverse and still emerging functions that affect critical cellular processes. This review summarizes how GSH synthesis is regulated in health and dysregulated in certain diseases, with an emphasis on the liver. This is because the liver plays a central role in the interorgan GSH homeostasis as plasma GSH and cysteine levels are largely determined by the sinusoidal efflux of hepatic GSH (Ookhtens and Kaplowitz, 1998). Some of the key functions of GSH are described in more detail before turning the attention to GSH synthesis.

\subsection{Detoxifying functions of GSH}

A major function of GSH is detoxification of xenobiotics and/or their metabolites. These compounds are electrophiles or electron-loving substances (Fig. 2, indicated as X) and form conjugates with GSH either spontaneously or enzymatically in reactions catalyzed by GSH-Stransferase (Meister, 1988). The conjugates formed are usually excreted from the cell or into bile as in the case of hepatocytes. GSH conjugates can undergo GGT-mediated cleavage of the $\gamma$-glutamyl moiety, leaving a cysteinyl-glycine conjugate. The cysteinyl-glycine bond is then cleaved by dipeptidase, resulting in a cysteinyl conjugate. This is followed by $\mathrm{N}$-acetylation of the cysteine conjugate, forming a mercapturic acid (Fig. 2). The metabolism of GSH conjugates to mercapturic acid begins either in the biliary tree, intestine or kidney, but the formation of the $\mathrm{N}$-acetylcysteine conjugate usually occurs in the kidney (DeLeve and Kaplowitz, 1990). In addition to exogenous compounds, many endogenously formed compounds also follow similar metabolic pathways. Although the majority of the conjugation reactions to GSH result in detoxification of the compound, occasionally the product itself is highly reactive (DeLeve and Kaplowitz, 1990). GSH conjugation irreversibly consumes intracellular GSH.

\subsection{Maintenance of essential thiol status}

GSH is the dominant non-protein thiol in mammalian cells; as such it is essential in maintaining the intracellular redox balance and the essential thiol status of proteins (Lu, 1999a). GSH undergoes thiol-disulfide exchange in a reaction catalyzed by thiol-transferase as follows:

$$
\text { Protein }-\mathrm{SSG}+\mathrm{GSH} \rightarrow \text { Protein }-\mathrm{SH}+\mathrm{GSSG}
$$

Since this reaction is a reversible reaction, the equilibrium is determined by the redox state of the cell, which depends on the concentrations of GSH and GSSG (proportional to the log of $\left.[\mathrm{GSH}]^{2} /[\mathrm{GSSG}]\right)(\mathrm{Lu}, 1999 \mathrm{a})$. Normally, cellular GSSG content is extremely low so that protein mixed disulfide formation is limited. The thiol-disulfide equilibrium within the cell is known to regulate a diverse number of metabolic processes including enzyme activity, transport activity, signal transduction, and gene expression via alteration of redox sensitive 
transcription factors such as activator protein-1 (AP-1), nuclear factor kappa B (NFkB) and p53 (Hutter et al., 1997; Lu, 1999a; Townsend et al., 2003).

\subsection{Anti-oxidant function of GSH}

All aerobic organisms are subject to a certain level of physiological oxidative stress from mitochondrial respiration. The intermediates that are formed, such as superoxide $\left(\mathrm{O}_{2}^{-} \bullet\right)$ and hydrogen peroxide $\left(\mathrm{H}_{2} \mathrm{O}_{2}\right)$, can lead to the production of toxic oxygen radicals that can cause lipid peroxidation and cell injury. To prevent this, the endogenously produced hydrogen peroxide is reduced by GSH in the presence of selenium-dependent GSH peroxidase (Fig. 3). In the process, GSH is oxidized to GSSG, which in turn is reduced back to GSH by GSSG reductase at the expense of NADPH, forming a redox cycle. Organic peroxides can be reduced by GSH peroxidase and GSH S-transferase. Hydrogen peroxide can also be reduced by catalase, which is present only in the peroxisome. In the mitochondria, GSH is particularly important because there is no catalase. Indeed, mitochondrial GSH is critical in defending against both physiologically and pathologically generated oxidative stress (Fernández-Checa et al., 1997;Garcia-Ruiz and Fernández-Checa, 2006).

Severe oxidative stress can overcome the ability of the cell to reduce GSSG to GSH leading to accumulation of GSSG. To protect the cell from a shift in the redox equilibrium, GSSG can be actively exported out of the cell or react with a protein sulfhydryl group leading to the formation of a mixed disulfide. Thus, severe oxidative stress depletes cellular GSH (Lu, 1999a).

\subsection{GSH as cysteine storage and the $\mathrm{y}$-glutamyl cycle}

Storage of cysteine is one of the most important functions of GSH because cysteine is extremely unstable extracellularly and rapidly auto-oxidizes to cystine, in a process that produces potentially toxic oxygen free radicals (Meister, 1988). Meister first described the $\gamma$-glutamyl cycle in the early 1970's, which allows GSH to serve as a continuous source of cysteine (Fig. 4). In this cycle, GSH is released from the cell by carrier mediated transporter(s) and the ectoenzyme GGT then transfers the $\gamma$-glutamyl moiety of GSH to an amino acid (the best acceptor being cystine), forming $\gamma$-glutamyl amino acid and cysteinylglycine. The $\gamma$-glutamyl amino acid can then be transported back into the cell to complete the cycle. Once inside the cell, the $\gamma$-glutamyl amino acid can be further metabolized to release the amino acid and 5-oxoproline, which can be converted to glutamate and used for GSH synthesis. Cysteinylglycine is broken down by dipeptidase to generate cysteine and glycine. Most cells readily take up cysteine. Once inside the cell, the majority of cysteine is incorporated into GSH, some is incorporated into protein, depending on the need of the cell, and some is degraded into sulfate and taurine (Meister, 1988). For most cells, the $\gamma$-glutamyl cycle allows GSH to be used as a continuous source of cysteine.

\subsection{GSH as a regulator of growth and death}

In cell types such as lymphocytes and fibroblasts, an increased GSH level is associated with an early proliferative response and is essential for the cell to enter the $\mathrm{S}$ phase (Shaw and Chou, 1986; Messina and Lawrence, 1989; Hamilos et al., 1989; Iwata et al., 1994; Poot et al., 1995). We also reported increased GSH levels during proliferation of rat hepatocytes such as plating primary cultures of rat hepatocytes under low density, which stimulates hepatocytes to shift from $G_{0}$ to $G_{1}$ phase of the cell cycle (Lu and Ge., 1992), and after 2/3 partial hepatectomy (PH) (Huang et al., 1998). The increase in hepatic GSH after PH occurred due to increased biosynthesis and prior to the onset of DNA synthesis (Huang et a., 1998). If this increase in GSH was blocked, liver regeneration was impaired (Huang et al., 2000a). Furthermore, GSH status directly correlated with the growth of liver cancer cells (Huang et al., 2000a). Carretero and colleagues have also shown that increased GSH promotes growth of metastatic melanoma 
cells in the liver (Carretero et al., 1999). The molecular mechanism of how GSH modulates cell proliferation remains largely speculative. GSH is known to modulate DNA synthesis by maintaining reduced glutaredoxin or thioredoxin, which are required for the activity of ribonucleotide reductase, the rate-limiting enzyme in DNA synthesis (Holmgren, 1981). Alternatively, an increase in the cellular GSH content may change the thiol-redox status of the cell, which in turn may affect the expression or activity of factors important for cell cycle progression.

GSH has also been implicated in the modulation of cell death. Apoptosis, one of the extremes of a continuous process of cell death, is characterized by morphological features such as chromatin condensation and fragmentation and interrnucleosomal DNA cleavage; while the other extreme is necrosis, which is characterized by rupture or fragmentation of the plasma membrane and ATP depletion (Garcia-Ruiz and Fernández-Checa, 2007). Both forms of cell death often coexist and share common pathways, such as involvement of the mitochondria (Lemasters, 2005). GSH modulates cell death at both extremes. GSH regulates redox state of specific thiol residues of proteins (such as NFKB, stress kinases and caspases) involved in cell death (Garcia-Ruiz and Fernández-Checa, 2007). GSH depletion occurs during apoptosis in many different cell types, secondary to increased reactive oxygen species (ROS), enhanced GSH efflux, and decreased GCL activity (see also Post-translational regulation of GCLC) (Hall, 1999; Franklin et al., 2003). In U937 and HepG2 cells, blocking GSH efflux prevented puromycin-induced apoptosis (Ghibelli et al, 1998), suggesting depletion of GSH played an important role in initiating apoptosis in some cell types. However, profound GSH depletion converts cell death induced by a variety of agents from apoptosis to necrosis (Hall, 1999), suggesting very high levels of ROS may overwhelm the apoptotic machinery. Indeed, GSH can influence cell death pathway by modulating the level of mitochondrial ROS, as has been demonstrated in the case of tumor necrosis factor $\alpha(\mathrm{TNF} \alpha)$ (Garcia-Ruiz and FernándezCheca, 2007). Mitochondrial GSH depletion leads to increased levels of ROS and reactive nitrogen species, mitochondrial dysfunction and ATP depletion. This can convert apoptotic to necrotic cell death (Garcia-Ruiz and Fernández-Checa, 2007).

\section{Synthesis of GSH}

GSH is synthesized in cytosol in virtually all cells (Meister and Anderson, 1983). The synthesis of GSH from its constituent amino acids involves two ATP-requiring enzymatic steps:

1. L-glutamate + L-cysteine + ATP $\rightarrow \gamma$-glutamyl-L-cysteine $+\mathrm{ADP}+\mathrm{Pi}$

2. $\quad \gamma$-glutamyl-L-cysteine + L-glycine $+\mathrm{ATP} \rightarrow \mathrm{GSH}+\mathrm{ADP}+\mathrm{Pi}$

The first step of GSH biosynthesis is considered rate limiting and catalyzed by glutamate cysteine ligase (GCL, EC 6.3.2.2; formerly $\gamma$-glytamylcysteine synthetase), which exhibits an absolute requirement for either $\mathrm{Mg}^{2+}$ or $\mathrm{Mn}^{2+}$. GCL is composed of a heavy or catalytic (GCLC, $\mathrm{Mr} \sim 73,000$ ) and a light or modifier (GCLM, $\mathrm{Mr} \sim 30,000$ ) subunit, which are encoded by different genes in species as divergent as humans and fruit flies (Yan and Meister, 1990; Huang et al., 1993a; Gipp et al., 1992; Gipp et al., 1995; Dalton et al., 2004). In contrast, yeast and bacteria have only a single gene (Dalton et al., 2004). For clarity, this review is focused only on the heterodimeric GCL. GCL may be dissociated under nondenaturing conditions by treatment with dithiothreitol (Seelig et al., 1984). GCLC obtained after this treatment exhibits all of the catalytic activity of the isolated enzyme as well as feedback inhibition by GSH (Seelig et al., 1984). GCLM is enzymatically inactive but plays an important regulatory function by lowering the $\mathrm{K}_{\mathrm{m}}$ of GCL for glutamate and raising the $\mathrm{K}_{\mathrm{i}}$ for GSH (Huang et al., 1993a; Huang et al., 1993b). Thus, the holoenzyme is catalytically more efficient and less subject to inhibition by GSH than GCLC alone. In rat, GCLC has a $\mathrm{K}_{\mathrm{m}}$ for glutamate that is about 10 -fold higher $(18.2 \mathrm{mM}$ ) than that for GCL (Huang et al., 1993a), which is higher than the cellular glutamate concentration in most tissues (Dalton et al., 2004; Chen et al., 2005). This suggests GCLC is 
inactive under physiological condition. However, GCL and GCLC's $\mathrm{K}_{\mathrm{m}}$ for glutamate in other species such as human, mouse and fruit fly do not differ as much (Dalton et al., 2004), raising the possibility that GCLC may possess some activity. This is further supported by the fact that mice deficient in the Gclm gene are viable but have markedly reduced tissue GSH levels (reduced by about 85 to $90 \%$ ) (Yang et al., 2002).

GCL is specific for the glutamyl moiety and is regulated physiologically by: (a) nonallosteric feedback competitive inhibition by GSH $\left(\mathrm{K}_{\mathrm{i}}=2.3 \mathrm{mM}\right)$ which involves binding of $\mathrm{GSH}$ to the glutamate and another site on the enzyme (Richman and Meister, 1975; Huang et al., 1988) and (b) availability of its precursor, L-cysteine (Meister and Anderson, 1983). The apparent $\mathrm{K}_{\mathrm{m}}$ values of GCL for glutamate and cysteine are 1.8 and $0.1-0.3 \mathrm{mM}$, respectively (Richman and Meister, 1975). The intracellular glutamate concentration is nearly 10-fold higher than the $\mathrm{K}_{\mathrm{m}}$ value but intracellular cysteine concentration approximates the apparent $\mathrm{K}_{\mathrm{m}}$ value (Bannai and Tateishi, 1986; Lu et al., 1992b).

The second step in GSH synthesis is catalyzed by GSH synthase (GS, EC 6.3.2.3, formerly known as GSH synthetase). This enzyme has not been studied as extensively as GCL. GS purified from rat kidney has a $\mathrm{Mr}$ of approximately 118,000 daltons, is composed of two apparently identical subunits (Oppenheimer et al., 1979). Mapping studies of the GS substrate binding sites indicate that the regions of the active site that bind glycine and the cysteinyl moiety of $\gamma$-glutamylcysteine are highly specific, while the L- $\gamma$-glutamyl moiety can be replaced by a variety of analogs (Oppenheimer et al., 1979). Due to the fact that $\gamma$ glutamylcysteine (product of GCL) is present at exceedingly low concentrations when GS is present, GCL is considered rate limiting (Dalton et al., 2004). Supporting this is the observation that overexpression of GS failed to increase GSH level whereas overexpression of GCL increased GSH level (Grant et al., 1997). GS is not subject to feedback inhibition by GSH. However, GS deficiency in humans can result in generalized lower GSH levels and dramatic metabolic consequences because the accumulated $\gamma$-glutamylcysteine is converted to 5oxoproline, which can cause severe metabolic acidosis, hemolytic anemia, and central nervous system damage (Shi et al., 1996). Although GS is generally thought not to be important in the regulation of GSH synthesis, accumulating evidence suggests GS may play an important role, at least in certain tissues and/or under stressful conditions. In response to surgical trauma, GSH levels and GS activity in skeletal muscle fell while GCL activity was unchanged (Luo et al., 1998). Additionally, increased rat GS and GCLC expression further enhanced GSH synthesis above that observed with increased GCLC expression alone (Huang et al., 2000b). Thus, it is important to also consider GS when studying regulation of GSH synthesis under stressful or pathological conditions.

\subsection{Factors that determine cysteine availability}

2.1.1. Diet and amino acid uptake-Under normal physiological conditions, the rate of GSH synthesis is largely determined by two factors, cysteine availability and GCL activity. Cysteine is derived normally from the diet, protein breakdown and in the liver, from methionine via transsulfuration (conversion of homocysteine to cysteine). Cysteine differs from other amino acids because its sulfhydryl form, cysteine, is predominant inside the cell whereas its disulfide form, cystine, is predominant outside the cell (Lu, 1999a). Cysteine readily autoxidizes to cystine in the extracellular fluid and cystine, once it enters the cell, is rapidly reduced to cysteine (Bannai and Tateishi, 1986). Therefore, the key factors that regulate the hepatocellular level of cysteine other than diet include membrane transport of cysteine (via the ASC system), cystine (via the $\mathrm{X}_{\mathrm{c}}{ }^{-}$system which is induced under oxidative stress or in culture) and methionine (via the L system) as well as the transsulfuration pathway (Kilberg, 1982; Bannai and Tateishi, 1986; Takada and Bannai, 1984). Other amino acid transport systems are 
important in cysteine transport for extrahepatic tissues but due to space limitation will not be discussed here.

\subsubsection{Methionine metabolism and the transsulfuration pathway-The}

transsulfuration pathway deserves special mention because this is a pathway that is particularly active in the liver, which allows the liver to effectively utilize methionine for GSH synthesis (Lu, 1999a). That cysteine can be synthesized from methionine was first demonstrated by Tarver and Schmidt in 1939 (Tarver and Schmidt, 1939). This pathway is termed the transsulfuration or the cystathionine pathway (Fig. 5). Outside of the liver, this pathway is absent or insignificant, either in normal or transformed tissues (Finkelstein, 1990). The activity of this pathway in the liver is markedly impaired or absent in the fetus and newborn infant, in cirrhotic patients, and in patients with homocystinemia (Mato et al., 1994).

The transsulfuration pathway is closely linked to the methionine metabolic pathway (Fig. 5). Methionine is an essential amino acid that is primarily metabolized in the liver. The first step in methionine metabolism is the formation of S-adenosylmethionine (SAMe) in a reaction catalyzed by methionine adenosyltransferase (MAT) (Finkelstein, 1990;Mato et al., 2002). SAMe is the principal biological methyl donor and participates in three key metabolic pathways in the liver - polyamine synthesis, transmethylation and transsulfuration ( $\mathrm{Lu}$ and Mato, 2008). Under normal conditions, most of the SAMe generated is used in transmethylation reactions (Finkelstein, 1990). In transmethylation, SAMe donates its methyl group to a large variety of acceptor molecules in reactions catalyzed by methyltransferase (MTs). Sadenosylhomocysteine (SAH) is generated as a product of transmethylation and is hydrolyzed to form homocysteine (Hcy) and adenosine through a reversible reaction catalyzed by SAH hydrolase. SAH is a potent competitive inhibitor of methylation reactions and prompt removal of adenosine and Hcy is required to prevent accumulation of SAH. Hcy can be remethylated to form methionine by two enzymes: methionine synthase (MS), which requires normal levels of folate and vitamin $\mathrm{B}_{12}$; and betaine homocysteine methyltransferase (BHMT), which requires betaine, a metabolite of choline. Remethylation of homocysteine via MS requires 5methyltetrahydrofolate (5-MTHF), which is derived from 5,10-methylenetetrahydrofolate (5,10-MTHF) in a reaction catalyzed by methylenetetrahydrofolate reductase (MTHFR). 5MTHF is then converted to tetrahydrofolate (THF) as it donates its methyl group and THF is converted to 5,10-MTHF. In the liver, homocysteine can also be converted to cysteine via the transsulfuration pathway. Here, homocysteine condenses with serine to form cystathionine in a reaction catalyzed by cystathionine $\beta$ synthase (CBS), which requires vitamin $\mathrm{B}_{6}$ as a cofactor. Cleavage of cystathionine, catalyzed by another vitamin $\mathrm{B}_{6}$-dependent enzyme cystathionase, then releases free cysteine for GSH synthesis (Finkelstein, 1990). All mammalian tissues express MAT and MS, whereas BHMT is limited to the liver and kidney (Lu and Mato, 2008). In the liver, SAMe inhibits MTHFR and MS and activates CBS (Lu and Mato, 2008). Thus, when SAMe is depleted, homocysteine is channeled to remethylation to regenerate SAMe; whereas when SAMe level is high, homocysteine is channeled to the transsulfuration pathway. Patients with liver cirrhosis often exhibit hypermethioninemia and have impaired methionine clearance because the activity of hepatic MAT is significantly impaired (Mato et al., 2002). This impairment has been postulated to be one of the mechanisms of a decreased hepatic GSH level (Mato et al., 1994). In support of this, administration of SAMe to patients with liver cirrhosis resulted in increased hepatic GSH level (Vendemiale et al., 1989).

2.1.3 Role of Y-glutamyltranspeptidase (GGT)_As mentioned above, GGT is the only enzyme located on the external surface of epithelial cells that is able to hydrolyze the peptidic bond of GSH to provide a continuous source of cysteine through the $\gamma$-glutamyl cycle. As such GGT plays an integral role in GSH homeostasis and has been traditionally regarded as a component of the cellular defense system against oxidative stress (Pompella et al., 2007). 
Indeed, many pro-oxidants that induce GCL expression also induce the expression of GGT (Chikhi et al., 1999; Zhang et al., 2006). Similar to GCL subunits, Nrf2 also is a positive regulator of GGT expression (Zhang et al., 2006). In addition, increased expression of GGT has been reported in many human tumors and is thought to confer drug resistance by providing GSH precursors more efficiently (Pompella et al., 2007). However, increased GGT expression does not always translate to increased GSH levels and recent literature suggests that GGT does more than just maintain availability of GSH precursors (Paolicchi et al., 2002). A recent paper showed that GGT was able to mediate extracellular detoxification of cisplatin (Paolicchi et al., 2003). It turns out that cysteinylglycine, the product of GGT-mediated hydrolysis of GSH (see Figure 4), reacts with cisplatin about 5-fold faster than GSH (Daubeuf et al., 2002), leading to decreased cellular accumulation of cisplatin (Paolicchi et al., 2003). Even more intriguing is the notion that GGT-mediated hydrolysis of GSH can create a low level of ROS, due to generation of the more reactive thiol cysteinylglycine, which can reduce ferric iron to ferrous iron and trigger an iron redox cycling with production of ROS (Paolicchi et al., 2002). This low level ROS generated by GGT-mediated catabolism may even participate in tumor progression (Pompella et al., 2007). Thus, GGT is more than just a provider of GSH precursor and its role in cancer involves more than just drug resistance.

\subsection{Regulation of GCL}

The activity of GCL is a major determinant of the rate of GSH synthesis. Changes in GCL activity can result from regulation at multiple levels affecting only GCLC or both GCLC and GCLM subunits. Transcriptional and post-transcriptional regulation of both subunits has been described. Post-transcriptional regulation includes both mRNA stabilization/destabilization and post-translational modification.

\subsubsection{Regulation of GCL catalytic subunit (GCLC)}

2.2.1.1 Transcriptional regulation of GCLC: A change in GCL activity is responsible for alteration in cell GSH in many conditions. Oxidative stress caused by a variety of agents and drug-resistant tumor cell lines are two conditions associated with increased cell GSH levels, GCL activity, GCLC mRNA levels and GCLC gene transcription (Mulcahy et al., 1994a; Mulcahy et al., 1994b; Mulcahy et al., 1995a; Godwin et al., 1992; Ishikawa et al., 1996; Woods et al., 1992; Shi et al., 1994; Liu et al., 1996; Yamane et al., 1998). While many of the above treatments tend to induce both GCLC and GCLM expression, we have reported selective induction of only the GCLC subunit at the transcriptional level when cultured rat hepatocytes are treated with insulin, hydrocortisone, or by lowering the initial plating cell density (Lu and Ge 1992a; Lu et al., 1992b; Cai et al., 1995; Cai et al., 1997). The physiologic significance of the hormone effect was confirmed using in vivo models such as insulin-deficient diabetic or adrenalectomized rats. Both exhibited lower hepatic GSH levels and GCL activity, which were prevented with hormone replacement (Lu et al., 1992b). These hormones did not raise baseline hepatic GSH levels or GCLC expression, instead they prevented the fall (Lu et al., 1992b). However, a recent paper showed that dexamethasone administration increased the basal expression of GCLC and GSH levels in the spiral ganglion of the mouse cochlea (Nagashima and Ogita, 2006). Thus, glucocorticoids may exert different tissue-specific effects. With regards to relevance to human situation, lower levels of GSH in the erythrocytes of diabetic patients and increased susceptibility to oxidative stress of these cells have been reported (Yoshida et al., 1995; Jain et al., 2000). Recently, Kim et al confirmed the effect of insulin on GSH levels and GCLC expression in rat hepatocytes and found that of the signaling pathways activated by insulin, PI3K/Akt/p70S6K are involved in mediating the effect while ERK, JNK and p38 MAPK are not (Kim et al., 2004). However, Li et al reported that insulin-mediated up-regulation of GSH synthesis in cardiac myocytes required PI3K, MEK and p38 MAPK (Li et al., 2003). Thus, different signaling pathways activated by insulin may be involved in mediating the up-regulation of GSH synthesis in different cell types. 
Rapid hepatocyte growth is another condition that is associated with increased GSH levels and GCLC expression. We first reported this when cultured hepatocytes were plated under low density (Lu and Ge 1992a; Cai et al., 1997). Lowering the initial plating density of hepatocytes effectively shifts adult rat hepatocytes from the $\mathrm{G}_{0}$ to $\mathrm{G}_{1}$ phase of the cell cycle, analogous to liver regeneration after PH or after cell death (Nakamura et al., 1983a; Nakamura et al., 1983b). Consistent with our findings in cultured rat hepatocytes, a doubling of the hepatic GSH level and an increase in the steady state mRNA levels of GCLC were noted at $12 \mathrm{hr}$ after $2 / 3$ PH (Huang et al., 1998). Increased GSH levels and GCLC transcription and mRNA levels also occur in human hepatocellular carcinoma (HCC) (Huang et al., 2000a). Since hepatocyte growth factor (HGF) is the most potent mitogen known for hepatocytes (Zarnegar and Michalopoulos, 1995), we investigated how HGF might influence GSH synthesis.

Interestingly, we found that HGF's mitogenic effect depends on the cell density (Yang et al., 2008). At subconfluent density, HGF acts as a mitogen, induced the expression of both GCL subunits (although low density itself induced the expression of GCLC only) and increased GSH levels. This increase in GSH was required for HGF's mitogenic effect. HGF did not exert a mitogenic effect at confluent cell density (Yang et al., 2008). It should be pointed out that HGF only acts as a mitogen in vivo when there is loss of cell-cell contact such as following $2 / 3 \mathrm{PH}$ (Zarnegar and Michalopoulos, 1995). Taken together, our data suggest hepatic GCLC gene expression is increased during rapid growth and since an increase in GCLC expression alone can lead to increased GSH level, hepatocytes may express more GCLM than GCLC. This notion is shared by others (Soltaninassab et al. 2000) but remains controversial, as the opposite, namely that the liver expresses more GCLC than GCLM has also been reported (Krzywanski et al., 2004; Chen et al., 2005; Lee et al., 2006). Still, how an increase in GCLC expression alone can increase GCL activity and GSH level can't be easily explained if GCLM is limiting.

Transforming growth factor- $\beta 1$ (TGF- $\beta 1$ ) has also been shown to regulate GSH synthesis at the level of GCLC in different cell types (Jardine et al., 2002; Fu et al., 2008). TGF- $\beta 1$ is a pleiotropic cytokine elevated in many chronic inflammatory disorders and is implicated in the pathogenesis of idiopathic pulmonary fibrosis and in liver fibrosis (Jardine et al., 2002; Fu et al., 2008). In type II alveolar epithelial cells, TGF- $\beta 1$ was found to inhibit the expression of GCLC (Jardine et al., 2002). Likewise, TGF- $\beta 1$ suppressed the expression of GCLC (no effect on GCLM) and lowered GSH levels in rat hepatic stellate cells (HSCs), which facilitated fibrogenesis (Fu et al., 2008). Interestingly, (-)-epigallocatechin-3-gallate (EGCG), the major constituent of green tea that has potent antioxidant action, was shown to block the inhibitory effect of TGF- $\beta 1$ on GCLC expression and GSH levels in HSCs and TGF- $\beta 1$-induced HSC activation (Fu et al., 2008). This may be an important mechanism of EGCG's antifibrotic effect.

In addition to above, several other conditions are also known to influence the steady state GCLC mRNA level. These include treatments with several anti-oxidants such as butylated hydroxyanisole (Eaton and Hamel, 1994; Borroz et al., 1994), 5,10-dihydroindeno[1,2-b] indole and tert-butyl hydroquinone (TBH) (Liu 1994 and 1996, Yang et al., 2002), zinc (Ha et al., 2006), melatonin (Urata et al., 1999), curcumin (Zheng et al., 2007), formation of Michael reaction acceptors (containing an electrophilic electron-deficient center that is susceptible to nucleophilic attack) by treatment with diethyl maleate (DEM) or phorone to produce GSH conjugates (Borroz et al., 1994; Cai et al., 1997), and lipid peroxidation products such as 4hydroxynonenal (HNE) and 15-deoxy-• $\bullet^{12,14}$-prostaglandin $\mathrm{J}_{2}\left(15 \mathrm{~d}-\mathrm{PGJ}_{2}\right)$ (Iles and Liu, 2005; Zhang et al., 2007; Chen et al., 2006; Lim et al., 2004). HNE is one of the major end products of lipid peroxidation and deserves special mention. It is present in normal human plasma at concentrations ranging from $0.1 \mu \mathrm{M}$ to $1.4 \mu \mathrm{M}$ and this can increase to over 10 times higher during oxidative stress in vivo (Zhang et al., 2007). Recently HNE has been shown to induce GCLC with concentrations found in human plasma, suggesting that the "basal" GCLC expression is under regulation by products of lipid peroxidation (Zhang et al., 2007). Inducers of Phase II detoxifying enzymes such as $\beta$-naphthoflavone ( $\beta$-NF) also transcriptionally 
activate GCLC (Mulcahy et al., 1997). Increased GCLC mRNA levels have also been reported in response to heat shock (Kondo et al., 1993). Cysteine deprivation has also been shown to induce GCLC expression (Lee et al., 2006). Thus, GCLC gene expression is up-regulated under conditions where increased cellular defense is necessary.

Many studies have focused on transcriptional regulation of GCLC at the promoter level. The 5 '-flanking regions of human, rat, and mouse GCL subunits have all been cloned (Mulcahy and Gipp, 1995b; Mulcahy et al., 1997; Galloway et al., 1997; Moinova and Mulcahy, 1998; Hudson and Kavanagh, 2000; Yang et al., 2001; Solis et al., 2002; Yang et al., 2005b). Consensus NFkB, Sp-1, AP-1, activator protein-2 (AP-2), metal response (MRE), and antioxidant response (ARE)/electrophile responsive (EpRE) elements have been identified in the human GCLC promoter. Many studies have identified a proximal AP-1 element ( -263 to -269) to be critical in mediating the effect of oxidative stress-induced increase in human GCLC transcription (Morales et al., 1997; Morales et al., 1998; Rahman et al., 1996; Rahman et al., 1998; Sekhar et al., 1997b). On the other hand, Mulcahy et al described a critical distal ARE element (ARE4), located $\sim 3.1 \mathrm{~kb}$ upstream of the transcriptional start site, which mediated constitutive and $\beta$-NF inducible expression in HepG2 cells (Mulcahy et al., 1997). They showed that the transcription factor Nrf2, possibly in complexes with other Jun or Maf proteins, was responsible for trans-activating the human GCLC promoter via binding to ARE4 in response to $\beta$-NF, pyrrolidine dithiocarbamate, and TBH (Wild et al., 1999; Erickson et al., 2002). While treatment of hepatocytes with phenolic antioxidants induce binding of $\mathrm{Nrf2/}$ JunD/Maf to human GCLC's ARE4 to trans-activate the gene, it appears that TGF- $\beta 1$ treatment in type II alveolar cells induced binding of Fra-1/c-Jun dimer to the internal AP-1 sequence of the ARE4 site and suppressed GCLC expression (Jardine et al., 2002). Thus, depending on the make up of the transcription factors bound to the cis-acting element, opposite effects may be observed. In the case of HNE, the molecular mechanism appears to be species-specific and is dependent on the dose used (Iles and Liu, 2005; Zhang et al., 2007). Thus, with pathologic HNE concentrations (10 $\mathrm{M}$ and higher) for rat GCLC, ERK activation was required for the HNE-mediated induction but for human GCLC, JNK activation was essential and Nrf2 was not required (Iles and Liu, 2005). However, with physiologic HNE concentrations, induction of GCLC required Nrf2 signaling (Zhang et al., 2007). Interestingly, the $1.8 \mathrm{~kb} 5$ '-flanking region of the rat GCLC does not contain any consensus ARE element (5'-G/ATG/TAG/ CNNNGCA/G-3') (Erickson et al., 2002), but the reporter activity driven by a recombinant rat GCLC-luciferase construct is induced by TBH (Yang et al., 2005a). In trying to elucidate how TBH induces the rat GCLC promoter activity, we uncovered interesting interactions between Nrf1 and Nrf2 with AP-1 and NFkB family members (Yang et al., 2005a).

Nrf1 and Nrf2 are members of the cap ' $n$ ' collar-basic leucine zipper proteins (CNC-bZIP) that can trans-activate ARE (Kwong et al., 1999; Jaiswal, 2004; Chan and Kwong, 2000). Nrf2 is kept in the cytosol by Keap1 under non-stressful conditions and undergoes proteosomal degradation (Kensler et al, 2007). Upon recognition of signals imparted by oxidative and electrophilic molecules, Nrf2 is released from Keap1, escapes proteosomal degradation and translocates to the nucleus to induce genes involved in defense and survival (Kensler et al., 2007). Although Nrf1 is similar to Nrf2 structurally, Nrf1's activity is not controlled by Keap1 (Wang and Chan, 2006). Instead, Nrf1 is primarily localized to the membrane of the endoplasmic reticulum and is released and translocates to the nucleus during endoplasmic reticulum stress (Wang and Chan, 2006). Nrf1 knockout mice die in utero but fetal hepatocytes and embryonal fibroblasts from these animals have lower GSH levels and are more susceptible to oxidative stress (Kwong et al., 1999; Chen et al., 2003). Mice lacking Nrf2 also exhibit lower GSH levels and are more susceptible to acetaminophen-induced liver injury (Chan et al., 2001). Nrf1 and Nrf2 knockouts have lower GCLC expression (Chan et al., 2001; Chen et al., 2003) and overexpression of Nrf1 and Nrf2 has been shown to induce the human GCLC promoter activity (Myhrstad et al., 2001; Wild et al., 1999). Interestingly TBH also induces 
the expression of rat GCLC and the activity of the rat GCLC promoter even though the promoter lacks ARE (Yang et al., 2001; Yang et al 2002). Instead AP-1 appears to be essential for TBHmediated induction of the rat GCLC gene (Yang et al., 2002). We examined whether Nrf1 and Nrf2 are important in the transcriptional regulation of the rat GCLC using Nrf1 and Nrf2 knockout (F1 and F2) and wild-type (WT) fibroblasts and found that Nrf1 and Nrf2 are important for the rat GCLC promoter activity despite absence of ARE. The mechanism involves the dependence of key family members of AP-1 and NFkB on Nrf1 and Nrf2 for their expression (Yang et al., 2005a). The basal protein, mRNA levels and nuclear binding activities of c-Jun, c-Fos, p50 and p65 were lower in F1 and F2 cells and exhibited a blunted response to TBH. Other AP-1 and NFאB family members were either unaffected (JunB, JunD) or increased (Fra-1, JAB1, and c-Rel). Overexpression of Nrf1 and Nrf2 restored the rat GCLC promoter activity and response to TBH in F1 and F2 cells, respectively. However, this was blocked if the AP-1 and NFאB binding sites are mutated. Fra-1 overexpression lowered endogenous GCLC expression and rat GCLC promoter activity while Fra-1 antisense has the opposite effects. Taken together, Nrf1 and Nrf2 regulate rat GCLC promoter by modulating the expression of key AP-1 and NFkB family members. These findings further illustrate the complex cross-talks among the different families of transcription factors and suggest many of the biological functions of the Nrf1 and Nrf2 may be related to their ability to modulate AP-1 and NFKB expression.

An area of controversy is the role of NFKB in modulation of the GCLC gene expression. Oxidative stress induces NFkB activity and Urata et al showed blocking activation of NFKB by anti-sense strategies prevented cytokines (TNF $\alpha$ and IL-1 $\beta$ )-induced increase in GCLC transcription in mouse endothelial cells (Urata et al., 1996). We also showed blocking the activation of NFKB prevented the increase in GCLC mRNA level induced by buthionine sulfoximine (BSO, an irreversible inhibitor of GCL) and TBH rat hepatocytes (Cai et al., 1997). Iwanaga et al also implicated the NFkB consensus element, but not AP-1 or ARE, in mediating the effect of ionizing radiation on GCLC expression in a human glioblastoma cell line (Iwanaga et al., 1998). However, NFkB consensus element was shown not to be involved in mediating the effect of TNF $\alpha$, okadaic acid and ionizing radiation on human GCLC expression in HepG2 cells (Morales et al., 1997; Morales et al., 1998; Sekhar et al., 1997b). The explanation for these discrepant results is unclear and may reflect species and/or cell type differences in mediating the effect of these agents on GCLC promoter. Our recent study using the rat GCLC promoter revealed that NFKB is important in maintaining the basal expression of GCLC and in mediating the effect of TNF $\alpha$-mediated induction of GCLC in rat hepatocytes (Yang et al., 2005b). NFKB can act on a consensus element present at -378 of the rat GCLC gene as well as induce the expression of AP-1 family member c-Jun to trans-activate AP-1 sites (Yang et al., 2005b). Thus, by acting directly and indirectly via inducing AP-1, NFאB is important in the expression of rat GCLC and perhaps human GCLC as well.

Although ARE/EpRE, AP-1 and NFאB may be responsible for basal expression and induction of GCLC by many of the pro- and anti-oxidants, recently c-Myc has been identified to also contribute to the basal expression and induction of human GCL under oxidative stress (Benassi et al., 2006). Thus, down-regulation of c-Myc lowered GSH while overexpression of c-Myc increased GSH. Two noncanonical c-Myc binding sites (CACATG, E box) are present in the human GCLC promoter at $-559 /-554$ and $-500 /-495$ and together with ARE4, are responsible for $\mathrm{H}_{2} \mathrm{O}_{2}$-induced GCLC promoter activity (Benassi et al., 2006). The signaling pathway activated by $\mathrm{H}_{2} \mathrm{O}_{2}$ involves ERK-mediated phosphorylation and activation of c-Myc (Benassi et al., 2006). Interestingly, an E-box motif has also been identified in the rat GCLC promoter, but it is present in the region that negatively regulate the GCLC promoter in lung epithelial L2 cells (Cheng et al., 2005). USF1 and USF2, but not c-Myc, can bind to this E-box and overexpression of either one can inhibit the promoter activity (Cheng et al., 2005). Given the similarities in how the human and rat GCLC respond to oxidative stress, whether oxidative 
stress can increase c-Myc binding to this E-box and displace USF1/2 to activate rat GCLC would be of interest.

2.2.1.2 Post-transcriptional regulation of GCLC: Post-transcriptional regulation includes regulation of the mRNA stability and post-translational regulation. In addition to increased gene transcription, DEM and 4-hydroxy-2-nonenal treatments have also been found to stabilize the GCLC mRNA (Sekhar et al., 1997a; Liu et al., 1998). The molecular mechanism of this effect remains unknown. Others and we have shown that GSH synthesis can be inhibited by hormone-mediated activation of various signal transduction pathways (Lu et al., 1991; Estrela et al., 1988) leading to an acute inhibition of GCL activity (Lu et al., 1991). Subsequent study showed that GCLC is phosphorylated directly by activation of protein kinase A (PKA), protein kinase C (PKC) or $\mathrm{Ca}^{2+}$-calmodulin kinase II (CMK) (Sun et al., 1996). Phosphorylation of GCLC was also demonstrated in cultured hepatocytes after treatment with dibutyryl cAMP (DBcAMP) or phenylephrine using specific antibodies which immunoprecipitated the phosphorylated GCLC. Interestingly there was basal GCLC phosphorylation, which increased when treated with DBcAMP or phenylephrine, suggesting GCLC may be under a basal inhibitory tone (Sun et al., 1996). The demonstration of phosphorylation of GCL using cultured hepatocytes suggests phosphorylation-dephosphorylation may be an important physiologic regulator of GCL. Since many pathologic and toxic conditions result in sustained increase in cytosolic free $\mathrm{Ca}^{2+}$, which can lead to activation of CMK and phosphorylation of GCLC, theoretically, inhibition of GCL may further contribute to toxicity under these conditions. The report by Lauterburg and Mitchell that toxic doses of acetaminophen administered in vivo suppressed hepatic GSH synthesis in rats (Lauterburg and Mitchell, 1982) raises this possibility.

Another post-translational regulation of GCLC is caspase 3-dependent cleavage that occurs during some forms of apoptotic cell death (Franklin et al., 2002; Franklin et al., 2003). GCLC was cleaved from the full-length $73 \mathrm{kDa}$ to a $60 \mathrm{kDa}$ form during apoptosis induced by TGF$\beta 1, \mathrm{TNF} \alpha$ and $\alpha$-Fas (Franklin et al., 2003). Cleavage of GCLC occurs at Asp ${ }^{499}$ within the sequence $\mathrm{AVVD}^{499} \mathrm{G}$, which lies upstream of $\mathrm{Cys}^{553}$ that is thought to be important for association with GCLM (Franklin et al., 2002). In the case of TGF- $\beta 1$, decreased GCLC mRNA together with cleavage of GCLC protein resulted in decreased GCL activity. GCLM protein level was not affected during this process (Franklin et al., 2003).

2.2.2. Regulation of GCL modifier subunit (GCLM)—As stated above, the light subunit of GCL plays a critical regulatory role on the overall function of the enzyme (Huang et al., 1993a; Huang et al., 1993b). Although the two GCL subunits are coordinately up-regulated by many inducers of oxidative stress and treatment with antioxidants (Galloway et al., 1997; Galloway et al., 1998; Moinova and Mulcahy, 1998; Moinova and Mulcahy, 1999; Wild et al., 1999, Erickson et al., 2002; Yang et al., 2005b; Zheng et al., 2007), there are also examples where the two subunits of GCL are differentially regulated. Gipp et al found no correlation between the steady state mRNA levels of the two GCL subunits (Gipp et al., 1995). We have shown that hormones and rapid growth transcriptionally activate only GCLC in hepatocytes (Cai et al., 1995; Cai et al., 1997; Huang et al., 1998, Huang et al, 2000b). Interestingly, thyroid hormone was reported to preferentially induce GCLM in astrocytes (Dasgupta et al, 2007) although the mechanism is not clear. Cysteine deprivation induces GCLM expression in hepatocytes, which was thought to facilitate holoenzyme formation and improve enzyme efficiency (Lee et al., 2006). Similar to their findings with the human GCLC promoter, Mulcahy and colleagues demonstrated that up-regulation of the human GCLM by $\beta$-NF involved binding of Nrf2 (possibly in complexes with other Jun or Maf proteins as in GCLC) to a functional ARE/EpRE site located at -302 of the human GCLM (Moinova and Mulcahy, 1999; Wild et al., 1999). However, Galloway and McLellan found that while an AP-1 site at -340 of human GCLM modulated basal expression of GCLM, neither the AP-1 site nor the ARE/EpRE site 
at -302 was involved in mediating the up-regulation of GCLM by TBH (Galloway et al., 1998). The reasons for these discrepancies are unclear although a follow-up study from Erickson et al attributed the discrepant results to a lack of functional consequence in the ARE mutant used by Galloway and McLellan (Erickson et al., 2002). Lipid peroxidation products like HNE and $15 \mathrm{~d}-\mathrm{PGJ}_{2}$ also induce GCLM although the signaling pathways appear to differ with pathological levels of HNE (Iles and Liu, 2005). With physiological HNE concentrations, Nrf2 signaling is required for GCLM induction (Zhang et al., 2007). Nrf2 is also required for GCLM induction by $15 \mathrm{~d}-\mathrm{PGJ}_{2}$ (Chen et al., 2006). Similar to GCLC, c-Myc also induced the human GCLM promoter activity under $\mathrm{H}_{2} \mathrm{O}_{2}$-induced stress (Benassia et al., 2006). There is a critical c-Myc-binding E-box at -1609/-1604 of the human GCLM promoter that in conjunction with the proximal ARE, mediate the full induction of the GCLM promoter when treated with $\mathrm{H}_{2} \mathrm{O}_{2}$ (Benassia et al., 2006). Mutation of either of these sites (E box or ARE) resulted in loss of activity. Transcription factors and cis-acting elements important for mouse and rat GCLM genes are similar to the human gene. Fibroblast cells derived from Nrf1 and Nrf2 knockout mice have lower GSH levels and reduced basal expression of GCLM (Kwong et al., 1999; Yang et al., 2005a). The rat GCLM promoter also has a functional ARE element ( -295 to -285 ) (Yang et al., 2005b). This ARE element is important for basal promoter activity as well as TNF $\alpha$-mediated induction of rat GCLM (Yang et al., 2005). AP-1, NFkB and Nrf2 are all positive regulators of the rat GCLM gene and are induced by TNF $\alpha$ treatment (Yang et

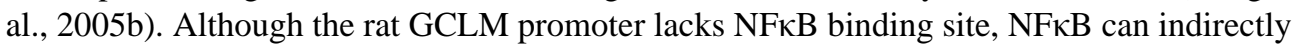
enhance GCLM expression by activating AP-1 (Yang et al., 2005b). Not all inducers of oxidative stress induce GCLM. Ethanol and TGF- $\beta 1$ treatments are known to induce oxidative stress, but GLCM expression was not increased (Lu et al., 1999b; Fu et al., 2008). The reason for this discordance is not clear and may depend partly on the relative expression of the two subunits in a given cell/tissue. Clearly, these findings point out there are important differences in the regulation of these two GCL subunits.

Post-transcriptional regulation of GCLM has been described with HNE, which increased the stability of GCLM mRNA by a mechanism that required de novo protein synthesis (Liu et al., 1998). This is different from its action on the GCLC mRNA stability, which did not require protein synthesis (see above). The molecular mechanisms underlying these differences remain to be elucidated.

\subsection{Regulation of glutathione synthase (GS)}

While much is known about GCL regulation, little attention has been paid to GS. The gene encoding GS was cloned in 1995 (Huang et al., 1995) but its transcriptional regulation has only been characterized recently after cloning of the rat and human GS promoters (Yang et al., 2002; Lee et al., 2005). 1,10-phenanthroline, a metal chelating agent, was reported to induce GS expression but the mechanism was not examined (Sun, 1997). Treatment of rats with monocrotaline, a pyrrolizidine alkaloid, was also shown to increase the activity of GS to a comparable level as that of GCL (Yan and Huxtable, 1996). Interestingly, Choi and colleagues described decreased hepatic GSH levels, which correlated with a fall in GS activity in Tat transgenic mice (Choi et al., 2000). In this model, there was no change in the GCLC protein level or GCL activity when measured under saturating substrate conditions. A decrease in the activity of GS alone without a change in GCL and a fall in muscle GSH levels were also described after surgical trauma in human skeletal muscle (Luo, et al., 1998). If GCL is ratelimiting, how can a change in GS activity influence the steady state GSH level? Although the specific activity of GS is normally 2 to 4 times that of GCL activity in normal liver (Lu et al., 1992b, Lu et al., 1999c), this may not be the case in other tissues. In fact, in normal human skeletal muscle, the specific activity of GS is only $36 \%$ higher than that of GCL (Luo et al., 1998). Surgical trauma selectively reduced GS activity, which probably became rate-limiting (Luo, et al., 1998). Collectively these results suggest regulation of GS has been overlooked 
and may be just as important in determining the overall GSH synthetic capacity as GCL under certain conditions and in non-hepatic tissues.

Using treatments that are known to influence the hepatic GCL subunit expression, we found that treatments that increase the expression of both subunits also increased the expression of GS (Huang et al., 2000b, Yang et al., 2005b; Yang et al., 2008). Thus, DEM, BSO, TBH, $\mathrm{TNF} \alpha$ and HGF treatment of rat hepatocytes and thioacetamide treatment of rats increased the expression of GS to a comparable level as previously observed with GCL subunits (Huang et al., 2000b; Yang et al. 2002; Yang et al., 2005b; Yang et al., 2008). In contrast, treatments that increase the expression of the heavy subunit alone such as insulin, hydrocortisone in cultured hepatocytes and ethanol feeding in vivo, had no influence on the expression of GS. There are some exceptions to this, one is liver regeneration after PH and the other is HCC. GS mRNA level increased in parallel to that of GCLC in both liver regeneration after PH and in human HCC (Huang et al., 2000a; Huang et al., 2000b). It is conceivable that when GCL is induced tremendously, the step catalyzed by GS may become limiting. A coordinated induction in the activity of both enzymes would facilitate the cell's ability to increase GSH production. The issue is whether the induction in GS can contribute to the increase in the capacity to synthesize GSH. We compared how treatments that increase only the expression of GCLC versus those that increase the expression of both GCLC and GS affect the capacity to synthesize GSH. Interestingly, treatment with insulin, hydrocortisone and ethanol, which induced only GCLC, increased the GSH synthesis capacity by 50 to $100 \%$ at the most (Lu et al., 1992b; Lu et al., 1999b). Treatment with thioacetamide and $2 / 3$ partial hepatectomy in rats, which induced both GCLC and GS expression, increased the GSH synthesis capacity by 161-200\% (Huang et al., 1998, Lu et al., 1999c). This supports the notion that increased GS expression can further enhance the capacity to synthesize GSH.

Another example where GCLC and GS are coordinately regulated but GCLM is unchanged is found in liver-specific retinoid X receptor $\alpha$ (RXR $\alpha$ ) knockout mice (Wu et al., 2004). RXR are members of the nuclear receptor family that regulate diverse developmental and physiological processes by binding to DNA response elements and modulating transcriptional activity (Wan et al., 2000). RXR are unique in their ability to form both homodimer and heterodimer to bind DNA. Different binding partner of RXR gives rise to a different DNAbinding specificity of the heterodimer, which in turn modulates distinct set of gene expression. Three distinct RXR genes (RXR $\alpha, \beta$ and $\gamma$ ) have been characterized in vertebrates and $\mathrm{RXR} \alpha$ is the most abundant isotype in the liver. Prompted by report that RXR $\alpha$ is important in liver regeneration (Imai et al., 2001), we examined changes in GSH homeostasis in mice with liver specific RXR $\alpha$ deletion (Wu et el., 2004). We found that hepatic GSH levels were $50 \%$ lower in the RXR $\alpha$ null mice. This is due to impairment in GSH synthetic capacity (40\% lower) and not precursor limitation (cysteine levels were unchanged). The mRNA levels of GCLC and GS were both lower (50\% and 30\%, respectively) while mRNA levels of GCLM were unchanged. These animals are more prone to develop ethanol-induced liver injury, which may be at least partly due to these changes. How RXR $\alpha$ regulates GCLC and GS remains to be elucidated.

Recent cloning of the rat and human GS promoters has allowed us to investigate molecular mechanisms of GS transcriptional regulation. The rat GS promoter contains functional AP-1 sites, some of which act as enhancers. It also contains a functional NF1 site that acts as a repressor (Yang et al., 2002). Basal expression of the rat GS gene in hepatocytes requires AP-1 and NFkB (Yang et al., 2002; Yang et al., 2005b). AP-1 is required for TBH-induced GS expression (Yang et al., 2002) and both AP-1 and NFאB are required for TNF $\alpha$ to induce GS (Yang et al., 2005b). Nrf1 is required for basal expression of GS in the mouse (Kwong et al., 1999) and Nrf1 and Nrf2 overexpression induced the human GS promoter activity (Lee et al., 2005). The cloned human GS promoter contains two regions with homology to the NFE2 
(nuclear factor erythroid 2) motif that are required for basal activity as mutation of these sites reduced the human GS promoter activity by $66 \%$ (Lee et al., 2005). Nrf1 and c-Jun binds to both sites while Nrf2 binds only to the distal NFE2 site. Thus, similar to human GCL subunits, Nrf1 and Nrf2 are important transcriptional regulators of the human GS gene. Recently, Nefedova et al. reported that all-trans retinoic acid (ATRA), which works via RXR, induced the expression of GS selectively (no effect on GCLC or GCLM) and GSH levels in myeloidderived suppressor cells (Nefedova et al., 2007). ATRA treatment for 48 hours also increased GSH levels in mononuclear cells isolated from patients with metastatic renal cell carcinoma, although whether GS expression was increased was not examined (Nefedova et al., 2007). ATRA failed to exert an effect on the GS promoter and had no effect on Nrf2 or NFkB expression. However, the effect of ATRA on GS expression was blocked if ERK1/2 was inhibited (Nefedova et al., 2007). Detailed signaling mechanism still remains to be elucidated. Post-transcriptional regulation of GS has not been reported.

\section{Dysregulation of GSH synthesis in aging and disease}

Although many conditions are known to be associated with low GSH levels (such as Parkinson's, HIV/AIDs, cystic fibrosis) (Townsend et al., 2003), not too many have been shown to be associated with a fall in GCL activity and/or GCL expression. Polymorphism of GCL subunits has received increasing attention. GCLC polymorphism has been shown to be associated with decreased GCLC expression in a patient with hemolytic anemia (Beutler et al., 1999), GSH levels and drug resistance among tumor cell lines (Walsh et al., 2001), decreased GCL activity and GSH levels in patients with schizophrenia (Gysin et al., 2007). GCLM polymorphism has been associated with impairment of NO-mediated coronary vasomotor function and risk of myocardial infarction (Nakamura et al., 2002; Nakamura et al., 2003). Whether these polymorphisms affect other diseases remain to be determined. The following discusses only conditions associated with a change in GCL activity and/or GCL expression that's not known to be due to polymorphism.

\subsection{Aging}

Liu and coworkers have systematically evaluated the effect of aging in rodents on GSH homeostasis in different tissues and found that GSH level falls in all tissues with age, due to a corresponding fall in GCL and GS gene expression (no change in GGT, GSH reductase expression, cysteine availability or GSSG as an indicator of oxidative stress) (Wang et al., 2003; Liu et al., 2004). Although aging is associated with a fall in GSH content in both genders, male mice had more dramatic fall in GSH levels and GCL mRNA levels in many tissues (Wang et al., 2003). Exogenous estrogen increased GCL, GS expression and increased GSH levels in livers of both male and female mice, but it had no effect in other tissues such as heart and brain (Liu et al., 2004). Taken together, these findings suggest that the age-dependent fall in GSH may contribute to many of the age-associated diseases. How aging affects the expression of GCL and GS at the molecular level remains largely unclear.

\subsection{Diabetes mellitus}

As discussed above under transcriptional regulation of GCLC, insulin deficiency lowers the expression of GCLC and reduced GSH content in erythrocytes of diabetic patients have been reported. High glucose by itself was also shown to reduce GCLC transcription in mouse endothelial cells (Urata et al., 1996). Recently, Masahiro et al showed that chronic hyperglycemia resulted in enhanced apoptosis in human brain endothelial cells, which was attenuated by insulin (Masahiro et al., 2006). This was related to insulin's ability to induce GCLC expression (GCLM was unchanged as in hepatocytes). This required PI3K/Akt/mTOR signaling and it resulted in nuclear translocation of Nrf2 (Masahiro et al., 2006). Taken together, these findings support the notion that decreased GCLC expression due to hyperglycemia and 
insulin deficiency can lead to decreased GSH levels that impair antioxidant defense. An important action of insulin is to increase the expression of GCLC.

\subsection{Cholestasis}

Cholestatic liver disease is a major cause of morbidity and mortality. Retention of toxic bile acids is believed to be a major mechanism for cell toxicity (Neuschwander-Tetri et al., 1996; Tan et al., 2007). Chronic retention of toxic bile acids can cause oxidative stress, apoptosis and fibrosis leading to cirrhosis. Although there is conflicting data, many groups showed a fall in GSH level in either livers of animals subjected to experimental cholestasis or hepatocytes treated with toxic bile acids (Neuschwander-Tetri et al., 1996; Montilla et al., 2000; Gumpricht, et al., 2000; Serviddio et al., 2004; Ebrahimkhani, et al., 2005; Demirbilek et al., 2006; ReyesGordillo, et al., 2007). This can further jeopardize antioxidant defense and contribute to injury. Some (Neuschwander-Tetri et al., 1996; Serviddio et al., 2004) but not others (Gumpricht, et al., 2000) showed a fall in GCL activity. One paper reported a fall in both GCLC and GCLM mRNA levels (Serviddio et al., 2004). Interestingly, ursodeoxycholic acid, the only treatment approved by the Food and Drug Administration for the treatment of primary biliary cirrhosis, a chronic cholestatic disorder, was shown to prevent the fall in GCL expression during chronic cholestasis (Serviddio et al., 2004) and increase GCL expression in cultured rat hepatocytes (Mitsuyoshi et al., 1999). The molecular mechanisms for changes in GCL expression during cholestasis or in response to ursodeoxycholic acid treatment remain unknown.

\subsection{Endotoxemia}

Lipopolysaccharide (LPS) is a major component of the outer membrane of all gram-negative bacteria that can trigger the synthesis and release of pro-inflammatory cytokines such as $\mathrm{TNF} \alpha$, interleukin $1 \beta$ (IL-1 $\beta$ ), and inducible nitric oxide synthase (iNOS) (Zhang et al., 2000; Su, 2002). Liver plays a central role in the clearing of gut-derived LPS (Su, 2002). Indeed, endotoxemia frequently occurs in patients with liver cirrhosis and the degree of endotoxemia correlates directly with the degree of liver failure (Su, 2002). Endotoxemia is also believed to participate in the pathogenesis of many liver diseases including alcoholic liver disease and nonalcoholic steatohepatitis (Su, 2002; Yang et al., 1997). GSH is an important variable that determines susceptibility to LPS-induced liver injury (Payabvash et al., 2006; Sun et al, 2006). In animal models, endotoxemia is known to lower GSH levels in the liver (Jaeschke, 1992; Payabvash et al., 2006) and in peritoneal macrophages and lymphocytes (Victor and De La Fuente, 2003). This occurs also in patients hospitalized for sepsis as lower blood GSH:GSSG ratios have been reported (Németh and Boda, 2001). Exogenous GSH suppressed LPS-induced systemic inflammatory response and reduced mortality (Sun et al., 2006). The molecular mechanism of GSH's protective effect may have to do with its ability to influence toll like receptor 4 (TLR 4) signaling. Thus, low GSH level potentiated LPS-induced mortality and TNF $\alpha$ secretion. This was demonstrated using Nrf2-l- mice and $\mathrm{N}$-acetylcysteine administration prevented these changes (Thimmulappa et al., 2006). The fall in GSH is multifactorial. Part of it is secondary to oxidative stress, which is well documented to occur during endotoxemia (Zhang et al., 2000). However, one study (Payabvash et al., 2006) showed that a major part of hepatic GSH depletion during endotoxemia is a fall in GCL activity, which as associated with a fall in GCLC mRNA level. In support for this is that a cysteine prodrug was unable to prevent the fall. On the other hand, nitric oxide (NO) inhibitor (both non-specific and iNOS specific) ameliorated the fall in GSH (Payabvash et al., 2006). This would suggest that hepatic GCLC expression is inhibited by an increased in NO level. However, the effect of NO on GCL expression is mixed and depends on cell type. In rat hepatocytes, NO exerted no influence on the basal GSH level or GCL expression but was involved in up-regulating GCL expression in response to IL-1 (Kuo et al., 1996). Also, treatment of rat aortic vascular smooth muscle cells with NO at physiological concentrations resulted in increased cell GSH level and expression of both GCL subunits (Moellering et al., 1998). These results appear to contradict 
finding reported in vivo (Payabvash et al., 2006). Suffice to say, the molecular mechanism of how GCL expression falls during endotoxemia and whether NO regulates GCL expression in vivo remain largely unknown.

\subsection{Alcoholic liver disease}

Patients with alcoholic liver disease are known to have low hepatic and plasma GSH levels (Vendemiale et al., 1989; Tsukamoto and Lu 2001; Lee et al., 2004). The reason for this is multi-factorial. Oxidative stress is one of the reasons that deplete GSH. Another is cysteine availability, which can be limited due to nutritional deficiency and multiple abnormalities of the methionine metabolic pathway that include reduced activities in MAT and trans-sulfuration enzymes (Tsukamoto and Lu, 2001). We reported that in addition to these abnormalities, patients hospitalized for alcoholic hepatitis have a 50\% fall in the steady state hepatic mRNA levels of GCLC and GS (no change in GCLM) (Lee et al., 2004). The mechanism for this is unclear but given that GSH is required for normal lymphocyte function (Hamilos et al., 1989; Hartl et al., 2005), these abnormalities may further contribute to the high morbidity and mortality of this disorder.

\subsection{Cancer and drug-resistant tumors}

Resistance to commonly used alkylating agents or platinum chemotherapeutic drugs is often multifactorial, involving altered drug transport, biotransformation and enhanced detoxification capacity (Lu, 1999a). Increased GSH levels and GCL expression occur in many tumors and have been implicated to confer drug and/or radiation resistance to tumors of ovarian, lung, prostate and colorectal origins (Lu, 1999a). We also found that GSH levels are higher in human liver cancer (Huang et al., 2000a). This was due to increased GCLC and GS (GCLM was unchanged) expression at the transcriptional level (Huang et al., 2000a). The increase in cell GSH is a major contributing factor to drug resistance by binding to or reacting with drugs, interacting with reactive oxygen moieties, preventing damage to proteins or DNA, or by participating in DNA repair processes. In most studies, GCLC is induced in resistant tumors and whether GCLM is affected is controversial. MRP (human multidrug resistance protein), a member of the superfamily of ATP-binding cassette membrane transporters, can confer resistance to multiple classes of chemotherapeutic agents (Kuo et al., 1998; Oguri et al., 1998). Several studies have shown coordinated overexpression of GCLC and MRP in drugresistant tumor cell lines, in human colorectal tumors and in human lung cancer specimens after platinum drug exposure (Kuo et al., 1998; Oguri et al., 1998). In contrast, no correlation was found between MRP and GCLM expression (Kuo et al., 1998). In some of these cancers, increased GCLC expression is associated with increased AP-1 (Yao et al., 1995; Huang et al., 2000a). The importance of GSH in cancer treatment is best illustrated by the fact that BSO, the irreversible inhibitor of GCL, is now often used as an adjuvant chemotherapeutic agent to sensitize tumor cells to the effects of chemotherapy (Reber et al., 1998; Alessio et al., 2004).

\subsection{Other conditions}

Many other conditions are also associated with dysregulated GSH synthesis. This includes uremia (Alhamdani, 2005), neurodegenerative diseases (Liu, et al., 2004), and pulmonary fibrosis (Walters et al., 2008). A fall in GCL activity has been reported in some of them. While much has been learned about what up-regulates GCL expression, we remain largely in the dark about what down-regulates GCL, especially in disease states.

\section{Summary and future directions}

Since the importance of GSH and its synthetic enzymes was realized more than half a century ago, much has been learned about how GSH synthesis is regulated. Studies in the past 15 years have elucidated the molecular signaling pathways that regulate GCL expression. Key cis-acting 
elements and transcription factors have been identified that are responsible for the induction of GCL under oxidative stress, treatment with anti-oxidants and insulin. Many acute and chronic diseases have associated GSH synthesis dysregulation and reduced expression of GCL and GS but the molecular mechanisms remain largely unknown. Polymorphism of GCL subunits has been reported in a handle of diseases and whether their effects are more generalized are unknown. Areas of future investigation should include identification and confirmation of GCL subunit polymorphisms in chronic diseases associated with oxidative stress and elucidation of the molecular mechanisms responsible for reduced GCL and GS expression in various disease states. Identifying these mechanisms may lead to development of therapies directed at either preventing or correcting these abnormalities. Ultimately, the goal is to translate these findings to prevent complications that can result from altered GSH synthesis.

\section{Acknowledgments}

This work was supported by NIH grant DK45334

\section{References}

Akerboom TP, Bilizer MM, Sies H. The relationship of biliary GSSG efflux and intracellular GSSG content in perfused rat liver. J Biol Chem 1982;257:4248-4252. [PubMed: 7068633]

Alessio MD, Cerella C, Amici C, Pesce C, Coppola S, Fanelli C, De Nicola M, Cristofanon S, Clavarino G, Bergamaschi A, Magrini A, Gualandi G, Ghibelli L. Glutathione depletion up-regulates Bcl-2 in BSO-resistant cells. FASEB J. 200410.1096/fj.04-1813fje

Alhamdani MSS. Impairment of glutathione biosynthetic pathway in uremia and dialysis. Nephrol Dial Transplant 2005;20:124-128. [PubMed: 15632350]

Bannai S, Tateishi N. Role of membrane transport in metabolism and function of glutathione in mammals. J Membrane Biol 1986;89:1-8. [PubMed: 2870192]

Benassi B, Fanciulli M, Fiorentino F, Porrello A, Chiorino G, Loda M, Zupi G, Biroccio A. c-Myc phosphorylation is required for cellular response to oxidative stress. Mol Cell 2006;21:509-519. [PubMed: 16483932]

Beutler EGT, Kondo T, Matsunaga AT. The molecular basis of a case of $\gamma$-glutamylcysteine synthetase deficiency. Blood 1999;94:2890-2894. [PubMed: 10515893]

Borroz KI, Buetler TM, Eaton DL. Modulation of $\gamma$-glutamylcysteine synthetase large subunit mRNA expression by butylated hydroxianisole. Toxicol Appl Pharmacol 1994;126:150-155. [PubMed: 7910420]

Cai J, Huang ZZ, Lu SC. Differential regulation of $\gamma$-glutamylcysteine synthetase heavy and light subunit gene expression. Biochem J 1997;326:167-172. [PubMed: 9337864]

Cai J, Sun WM, Lu SC. Hormonal and cell density regulation of hepatic $\gamma$-glutamylcysteine synthetase gene expression. Molecular Pharmacol 1995;48:212-218.

Carretero J, Obrador E, Anasagasti MJ, Martin JJ, Vidal-Vanaclocha F, Estrela JM. Growth-associated changes in glutathione content correlate with liver metastatic activity of B16 melanoma cells. Clin Exp Metastasis 1999;17:567-574. [PubMed: 10845555]

Chan JY, Kwong M. Impaired expression of glutathione synthetic enzyme genes in mice with targeted deletion of the Nrf2 basic-leucine zipper protein. Biochimica et Biophysica Acta 2000;1517:19-26. [PubMed: 11118612]

Chan K, Han XD, Kan YW. An important function of Nrf2 in combating oxidative stress: Detoxification of acetaminophen. Proc Nat Acad Sci USA 2001;98:4611-4616. [PubMed: 11287661]

Chen L, Kwong M, Lu R, Ginzinger D, Lee C, Leung L, Chan JY. Nrf1 Is Critical for Redox Balance and Survival of Liver Cells during Development. Mol Cell Biol 2003;23:4673-4686. [PubMed: 12808106]

Chen Y, Shertzer HG, Schneider SN, Nebert DW, Dalton TP. Glutamate cysteine ligase catalysis. Dependence on ATP and modifier subunit for regulation of tissue glutathione levels. J Biol Chem 2005;280:33766-33774. [PubMed: 16081425] 
Chen ZH, Yoshida Y, Saito Y, Sekine A, Noguchi N, Niki E. Induction of adaptive response and enhancement of PC12 cell tolerance by 7-hydroxycholesterol and 15-deoxy-delta(12,14)prostaglandin $\mathrm{J} 2$ through up-regulation of cellular glutathione via different mechanisms. J Biol Chem 2006;281:14440-14445. [PubMed: 16565077]

Cheng LL, Li B, Luo JD, Tu HB, Liu QC, Ran P. Identification of an E-box motif as a transcriptional repressor element in the proximal promoter region of the GCLC gene in rat lung epithelial L2 cells. Free Rad Biol Med 2005;39:1030-1040. [PubMed: 16198230]

Chikhi N, Holic N, Guellaen G, Laperche Y. Gamma-glutamyl transpeptidase gene organization and expression: a comparative analysis in rat, mouse, pig and human species. Comp Biochem Physiol 1999;122:367-380.

Choi J, Liu RM, Kundu RK, Sangiorgi F, Wu W, Maxson R, Forman HJ. Molecular emchanism of decreased glutathione content in human immunodeficiency virus type 1 Tat-transgenic mice. J Biol Chem 2000;275:3693-3698. [PubMed: 10652368]

Dalton TP, Chen Y, Schneider SN, Nebert DW, Shertzer HG. Genetically altered mice to evaluate glutathione homeostasis in health and disease. Free Rad Biol Med 2004;37:1511-1526. [PubMed: 15477003]

Dasgupta A, Das S, Sarkar PK. Thyroid hormone promotes glutathione synthesis in astrocytes by up regulation of glutamate cysteine ligase through differential stimulation of its catalytic and modular subunit mRNAs. Free Rad Biol Med 2007;42:617-626. [PubMed: 17291985]

Daubeuf S, Leroy P, Paolicchi A, Pompella A, Wellman M, Galteau MM, Visvikis A. Enhanced resistance of HeLa cells to cisplatin by overexpression of g-glutamyltransferase. Biochem Pharmacol 2002;64:207-216. [PubMed: 12123741]

DeLeve L, Kaplowitz N. Importance and regulation of hepatic GSH. Sem Liver Dis 1990;10:251-266.

Demirbilek S, Akn M, Gürünlüoglu, Aydin NE, Emre MH, Tas E, Aksoy RT, Ay S. The NF-кB inhibitors attenuate hepatic injury in bile duct ligated rats. Pediatr Surg Intr 2006;22:655-663.

Eaton DL, Hamel DM. Increase in $\gamma$-glutamylcysteine synthetase activity as a mechanism for butylated hydroxyanisole-mediated elevation of hepatic glutathione. Toxicol Appl Pharmacol 1994;126:145149. [PubMed: 7910419]

Ebrahimkhani MR, Sadeghipour H, Dehghani M, Kiani S, Payabvash S, Riazi K, Honar H, Pasalar P, Mirazi N, Amanlou M, Farsam H, Dehpour AR. Homocysteine laterations in experimental cholestasis and its subsequent cirrhosis. Life Sci 2005;76:2497-2512. [PubMed: 15763080]

Erickson AM, Nevarea Z, Gipp JJ, Mulcahy RJ. Identification of a variant antioxidant response element in the promoter of the human glutamate-cysteine ligase modifier subunit gene. J Biol Chem 2002;277:30730-30737. [PubMed: 12070177]

Estrela JM, Gil F, Vila JM, Vina J. $\alpha$-Adrenergic modulation of glutathione metabolism in isolated rat hepatocytes. Am J Physiol 1988;255:E801-805. [PubMed: 3202158]

Fernández-Checa J, Kaplowitz N, Garcia-Ruiz C, Colell A, Miranda M, Mai M, Ardite E, Morales A. GSH transport in mitochondria: defense against TNF-induced oxidative stress and alcohol-induced defect. Am J Physiol 1997;273:G7-G17. [PubMed: 9252504]

Finkelstein JD. Methionine metabolism in mammals. J Nutr Biochem 1990;1:228-237. [PubMed: 15539209]

Franklin CC, Krejsa CM, Pierce RH, White CC, Fausto N, Kavanagh TJ. Caspase-3-dependent cleavage of the gluatamate-L-cysteine ligase catalytic subunit during apoptotic cell death. Am J Pathol 2002;160:1887-1894. [PubMed: 12000740]

Franklin CC, Rosenfled-Franklin ME, White C, Kavanagh TJ, Fausto N. TGF $\beta 1$-induced suppression of glutathione antioxidant defenses in hepatocytes: caspase-dependent posttranslational and caspaseindependent transcriptional regulatory mechanisms. FASEB J. 200310.1096/fj.02-0867fje

$\mathrm{Fu}$ Y, Zhou YJ, Lu SC, Chen AP. Epigallocatechin-3-gallate inhibits growth of activated hepatic stellate cells by enhancing the capacity of glutathione synthesis. Mol Pharmacol 2008;73:1465-73. [PubMed: 18230716]

Galloway DC, Blake DG, Shepherd AG, McLellan LI. Regulation of human $\gamma$-glutamylcysteine synthetase: co-ordinate induction of the catalytic and regulatory subunits in HepG2 cells. Biochem J 1997;328:99-104. [PubMed: 9359839] 
Galloway DC, McLellan LI. Inducible expression of the $\gamma$-glutamylcysteine synthetase light subunit by t-butylhydroquinone in HepG2 cells is not dependent on an antioxidant-responsive element. Biochem J 1998;336:535-539. [PubMed: 9841862]

Garcia-Ruiz C, Fernández-Checa JC. Mitochondrial glutathione: hepatocellular survival-death switch. J Gastroenterol Hepatol 2006;21:S3-6. [PubMed: 16958667]

Garcia-Ruiz C, Fernández-Checa JC. Redox regulation of hepatocyte apoptosis. J Gastroenterol Hepatol 2007;22:S38-42. [PubMed: 17567462]

Ghibelli L, Fanelli C, Rotilio G, Lafavia E, Coppola S, Colussi C, Civitareale P, Ciriolo MR. Rescue of cells from apoptosis by inhibition of active GSH extrusion. FASEB J 1998;12:479-486. [PubMed: 9535220]

Gipp JJ, Bailey HH, Mulcahy RT. Cloning and sequence of the cDNA for the light subunit of human liver $\gamma$-glutamylcysteine synthetase and relative mRNA levels for heavy and light subunits in human normal tissues. Biochem Biophys Res Comm 1995;206:584-589. [PubMed: 7826375]

Gipp JJ, Chang C, Mulcahy RT. Cloning and nucleotide sequence of a full-length cDNA for human liver $\gamma$-glutamylcysteine synthetase. Biochem Biophys Res Comm 1992;185:29-35. [PubMed: 1350904]

Godwin AK, Meister A, O’Dwyer PJ, Huang CS, Hamilton TC, Anderson ME. High resistance to cisplatin in human ovarian cancer cell lines is associated with marked increase of glutathione synthesis. Proc Natl Acad Sci USA 1992;89:3070-3074. [PubMed: 1348364]

Grant CM, MacIver FH, Dawes IW. Glutathione synthetase is dispensable for growth under both normal and oxidative stress conditions in the yeast Saccharomyces cerevisiae due to an accumulation of the dipeptide $\gamma$-glutamylcysteine. Mol Bio Cell 1997;8:1699-1707. [PubMed: 9307967]

Gumpricht E, Devereaux MW, Dahl RH, Sokol RJ. Glutathione status of isolated rat hepatocytes affects bile acid-induced cellular necrosis but not apoptosis. Toxicol Appl Pharmacol 2000;164:102-111. [PubMed: 10739750]

Gysin R, Kraftsik R, Sandell J, Bovet P, Chappuis C, Conus P, Deppen P, Preisig M, Ruiz V, Steullet P, Tosic M, Werge T, Cuenod M, Do KQ. Impaired glutathione synthesis in schizophrenia: convergent genetic and functional evidence. Proc Nat'l Acad Sci USA 2007;104:16621-16626.

Ha KN, Chen Y, Cai J, Sternberg P Jr. Increased glutathione synthesis through an ARE-Nrf2-dependent pathway by zinc in the RPE: Implication for protection against oxidative stress. Invest Ophthalmol Vis Sci 2006;47:2709-2715. [PubMed: 16723490]

Hall AG. The role of glutathione in the regulation of apoptosis. Eur J Clin Invest 1999;29:238-245. [PubMed: 10202381]

Hamilos DL, Zelarney P, Mascali JJ. Lymphocyte proliferation in glutathione-depleted lymphocytes: direct relationship between glutathione availability and the proliferative response. Immunopharmacology 1989;18:223-235. [PubMed: 2575086]

Hartl D, Starosta V, Maler K, Beck-Speler I, Rebhan C, Becker BF, Latzin P, Fischer R, Ratjen F, Huber RM, Rietschel E, Krass-Etschmann S, Greise M. Inhaled glutathione decreases PGE2 and increases lymphocytes in cystic fibrosis lungs. Free Rad Biol Med 2005;39:463-472. [PubMed: 16043018]

Hogg N. The biochemistry and physiology of S-nitrosothiols. Ann Rev Pharmacol Toxicol 2002;42:585600. [PubMed: 11807184]

Holmgren A. Regulation of ribonucleotide reductase. Current Topics in Cellular Regulation 1981;19:4776. [PubMed: 7037315]

Huang C, Anderson ME, Meister A. Amino acid sequence and function of the light subunit of rat kidney $\gamma$-glutamylcysteine synthetase. J Biol Chem 1993a;268:20578-20583. [PubMed: 8104188]

Huang C, Chang L, Anderson ME, Meister A. Catalytic and regulatory properties of the heavy subunit of rat kidney $\gamma$-glutamylcysteine synthetase. J Biol Chem 1993b;268:19675-19680. [PubMed: 8103521]

Huang C, He W, Meister A, Anderson ME. Amino acid sequence of rat kidney glutathione synthetase. Proc Natl Acad Sci USA 1995;92:1232-1236. [PubMed: 7862666]

Huang CS, Moore WR, Meister A. On the active site thiol of $\gamma$-glutamylcysteine synthetase: relationship to catalysis, inhibition, and regulation. Proc Nat'l Acad Sci, USA 1988;85:2464-68.

Huang ZZ, Chen CJ, Zeng ZH, Yang HP, Oh J, Chen LX, Lu SC. Mechanism and significance of increased glutathione level in human hepatocellular carcinoma and liver regeneration. FASEB J. 2000a10.1096/ fj.00-0445fje 
Huang ZZ, Li H, Cai J, Kuhlenkamp J, Kaplowitz N, Lu SC. Changes in glutathione homeostasis during liver regeneration in the rat. Hepatology 1998;27:147-153. [PubMed: 9425930]

Huang ZZ, Yang HP, Chen CJ, Zeng ZH, Lu SC. Inducers of $\gamma$-glutamylcysteine synthetase and their effects on glutathione synthetase expression. Biochim Biophys Acta 2000b;1493:48-55. [PubMed: 10978506]

Hudson FN, Kavanagh TJ. Cloning and characterization of the proximal promoter region of the mouse glutamate-L-cysteine ligase regulatory subunit gene. Biochim Biophys Acta 2000;1492:447-451. [PubMed: 10899580]

Hutter DE, Till BG, Greene JJ. Redox state changes in density-dependent regulation of proliferation. Exp Cell Res 1997;232:435-438. [PubMed: 9168823]

Hwang C, Sinsky AJ, Lodish HF. Oxidized redox state of glutathione in the endoplasmic reticulum. Science 1992;257:1496-1502. [PubMed: 1523409]

Iles KE, Liu RM. Mechanisms of glutamate cysteine ligase (GCL) induction by 4-hydroxynonenal. Free Rad Biol Med 2005;38:547-556. [PubMed: 15683710]

Imai T, Jiang M, Kastner P, Chambon P, Metzger D. Selective ablation of retinoid X receptor a in hepatocytes impairs their lifespan and regenerative capacity. Proc Natl Acad Sci, USA 2001;98:4581-4586. [PubMed: 11287642]

Ishikawa T, Bao JJ, Yamane Y, Akimaru K, Frindrich K, Wright CD, Kuo MT. Coordinated induction of $M R P / G S$ - $X$ pump and $\gamma$-glutamylcysteine synthetase by heavy metals in human leukemia cells. $\mathrm{J}$ Biol Chem 1996;271:14981-14988. [PubMed: 8663001]

Iwanaga M, Mori K, Iida T, Urata Y, Matsuo T, Wasunaga A, Shibata S, Kondo T. Nuclear factor kappa B dependent induction of gamma-glutamylcysteine synthetase by ionizing radiation in T98G human gliobastoma cells. Free Radical Biol Med 1998;24:1256-1268. [PubMed: 9626582]

Iwata S, Hori T, Sato N, Ueda-Taniguchi Y, Yamabe T, Nakamura H, Masutani H, Yodoi J. Thiolmediated redox regulation of lymphocyte proliferation. Possible involvement of adult $\mathrm{T}$ cell leukemia-derived factor and glutathione in transferrin receptor expression. J Immunol 1994;152:5633-5642. [PubMed: 8207197]

Jaeschke H. Enhanced sinusoidal glutathione efflux during endotoxin-induced oxident stress in vivo. Am J Physiol Gastrointest Liver Physiol 1992;263:G63-68.

Jain SK, McVie R, Smith T. Vitamin E supplementation restores glutathione and malondialdehyde to normal concentrations in erythrocytes of type I diabetic children. Diabetes Care 2000;23:1389-1394. [PubMed: 10977039]

Jaiswal AK. Nrf2 signaling in coordinated activation of antioxidant gene expression. Review Free Rad Biol Med 2004;36:1199-1207.

Johnsen O, Murphy P, Prydz H, Kolsto AB. Interaction of the CNC-bZIP factor TCF11/LCR-F1/Nrf1 with MafG: binding-site selection and regulation of transcription. Nuc Acid Res 1998;26:512-520.

Kaplowitz N, Aw TY, Ookhtens M. The regulation of hepatic GSH. Ann Rev Pharm Toxicol 1985;25:714-744.

Kensler TW, Wakabayashi N, Biswal S. Cell survival responses to environmental stresses via the Keap1Nrf2-ARE pathway. Annu Rev Pharmacol, Toxicol 2007;47:89-116. [PubMed: 16968214]

Kilberg MS. Amino acid transport in isolated rat hepatocytes. J Membrane Biol 1982;69:1-12. [PubMed: 6811749]

Kim SK, Woodcroft KJ, Khodadadeh SS, Novak RF. Insulin signaling regulates $\gamma$-glutamylcysteine ligase catalytic subunit expression in primary cultured rat hepatocytes. J Pharmacol Exp Therap 2004;311:99-108. [PubMed: 15169830]

Kondo T, Yoshida K, Urata Y, Goto S, Gasa S, Taniguchi N. $\gamma$-Glutamylcysteine synthetase and active transport of glutathione S-conjugate are responsive to heat shock in K562 erythroid cells. J Biol Chem 1993;268:20366-20372. [PubMed: 8104187]

Krzywanski DM, Dickinson DA, Iles KE, Wigley AF, Franklin CC, Liu RM, Kavanagh TJ, Forman HJ. Variable regulation of glutamate cysteine ligase subunit proteins affect glutathione biosynthesis in response to oxidative stress. Arch Biochem Biophys 2004;423:116-125. [PubMed: 14871475]

Kuo MT, Bao JJ, Furuichi M, Yamane Y, Gomi A, Savaraj N, Masuzawa T, Ishikawa T. Frequent coexpression of MRP/GS-X pump and $\gamma$-glutamylcysteine synthetase mRNA in drug-resistant cells, 
untreated tumor cells and normal mouse tissues. Biochem Pharmacol 1998;55:605-615. [PubMed: 9515571]

Kuo PC, Abe KY, Schroeder RA. Interleukin-1-induced nitric oxide production modulates glutathione synthesis in cultured rat hepatocytes. Am J Physiol 1996;40:C851-C862. [PubMed: 8843715]

Kwong M, Kan YW, Chan JY. The CNC basic leucine zipper factor, Nrf1, is essential for cell survival in response to oxidative stress-inducing agents. J Biol Chem 1999;274:37491-37498. [PubMed: 10601325]

Lauterburg BH, Mitchell JR. Toxic doses of acetaminophen suppress hepatic glutathione synthesis in rats. Hepatology 1982;2:8-12. [PubMed: 7054070]

Lee JI, Kang J, Stipanuk MH. Differential regulation of glutamate-cysteine ligase subunit expression and increased holoenzyme formation in response to cysteine deprivation. Biochem J 2006;393:181-190. [PubMed: 16137247]

Lee TD, Sadda ME, Mendler MH, Bottiglieri T, Kanel G, Mato JM, Lu SC. Abnormal hepatic methionine and GSH metabolism in patients with alcoholic hepatitis. Alcoholism: Clin Exp Res 2004;28:173181.

Lee TD, Yang HP, Whang J, Lu SC. Cloning and characterization of the human glutathione synthetase 5'-flanking region. Biochem J 2005;390:521-528. [PubMed: 15890065]

Lemasters JJ. Dying a thousand deaths: redundant pathways from different organelles to apoptosis and necrosis. Gastroenterology 2005;129:351-360. [PubMed: 16012960]

Li S, Li X, Rozanski GJ. Regulation of glutathione in cardiac myocytes. J Mol Cell Cardiol 2003;35:11451152. [PubMed: 12967637]

Lim SY, Jang JH, Lu SC, Rahman I, Surh YJ. 15-Deoxy ${ }^{12,14}$-Prostaglandin J 2 protects against nitorsative neuronal PC12 cell death through up-regulation of intracellular glutathione synthesis. J Biol Chem 2004;279:46263-46270. [PubMed: 15319433]

Liu H, Wang H, Shenvi S, Hagen TM, Liu RM. Glutathione metabolism during aging and in Alzheimer disease. Ann N Y Acad Sci 2004;1019:346-349. [PubMed: 15247041]

Liu RM, Gao L, Choi J, Forman HJ. $\gamma$-Glutamylcysteine synthetase: mRNA stabilization and independent subunit transcription by 4-hydroxy-2-nonenal. Am J Physiol 1998;275:L861-L869. [PubMed: 9815102]

Lu SC. Regulation of hepatic glutathione synthesis: Current concept and controversies. FASEB J 1999a; 13:1169-1183. [PubMed: 10385608]

Lu SC, Kuhlenkamp J, Garcia-Ruiz C, Kaplowitz N. Hormone-mediated down-regulation of hepatic GSH synthesis in the rat. J Clin Invest 1991;88:260-269. [PubMed: 1647417]

Lu SC, Ge J. Loss of suppression of GSH synthesis under low cell density in primary cultures of rat hepatocytes. Am J Physiol 1992a;263:C1181-1189. [PubMed: 1476163]

Lu SC, Ge J, Kuhlenkamp J, Kaplowitz N. Insulin and glucocorticoid dependence of hepatic $\gamma$ glutamylcysteine synthetase and GSH synthesis in the rat: Studies in cultured hepatocytes and in vivo. J Clin Invest 1992b;90:524-532. [PubMed: 1353765]

Lu SC, Huang ZZ, Yang J, Tsukamoto H. Effect of ethanol and high fat feeding on hepatic $\gamma$-glutamatecysteine ligase subunit expression in the rat. Hepatology 1999b;30:209-214. [PubMed: 10385658]

Lu SC, Huang ZZ, Yang H, Tsukamoto H. Effect of thioacetamide on hepatic $\gamma$-glutamylcysteine synthetase subunit expression. Tox Appl Pharmacol 1999c;159:161-168.

Lu SC, Mato JM. S-adenosylmethionine in cell growth, apoptosis and liver cancer. J Gastroenterol Hepatol 2008;1:S73-7. [PubMed: 18336669]

Luo JL, Hammarqvist F, Andersson K, Wernerman J. Surgical trauma decreases glutathione synthetic capacity in human skeletal muscle tissue. Am J Physiol 1998;275:E359-365. [PubMed: 9688640]

Masahiro O, Naotsuka O, Alexander SJ, Aw TK. Nrf2-dependent glutamate-L-cysteine ligase catalytic subunit expression mediates insulin protection against hyperglycemia-induced brain endothelial cell apoptosis. Curr Neurovasc Res 2006;3:249-261. [PubMed: 17109620]

Mato, JM.; Alvarez, L.; Corrales, FJ.; Pajares, MA. S-adenosylmethionine and the liver. In: Arias, IM.; Boyer, JL.; Fausto, N.; Jakoby, WB.; Schachter, DA.; Shafritz, DA., editors. The Liver: Biology and pathobiology. Vol. 3. Raven Press, Ltd; New York: 1994. p. 461-470. 
Mato JM, Corrales FJ, Lu SC, Avila MA. S-Adenosylmethionine: a control switch that regulates liver function. FASEB J 2002;16:15-26. [PubMed: 11772932]

Meister, A. Glutathione. In: Aria, IM.; Jakoby, WB.; Popper, H.; Schachter, D.; Shafritz, DA., editors. The Liver: Biology and Pathobiology. Vol. 2. Raven Press; New York: 1988. p. 401-417.

Meister A, Anderson ME. Glutathione. Ann Rev Biochem 1983;52:711-760. [PubMed: 6137189]

Meredith MJ, Reed DJ. Status of the mitochondrial pool of glutathione in the isolated hepatocyte. J Biol Chem 1982;257:3747-3753. [PubMed: 7061508]

Messina JP, Lawrence DA. Cell cycle progression of glutathione-depleted human peripheral blood mononuclear cells is inhibited at S phase. J Immunol 1989;143:1974-1981. [PubMed: 2789253]

Mitsuyoshi H, Nakashima T, Sumida Y, Yoh T, Nakajima Y, Ishikawa H, Inaba K, Sakamoto Y, Okanoue T, Kashima K. Ursodeoxycholic acid protects hepatocytes against oxidative injury via induction of antioxidants. Biochem Biophys Res Commun 1999;263:537-542. [PubMed: 10491327]

Moellering D, McAndrew J, Patel RP, Cornwell T, Lincoln T, Cao X, Messina JL, Forman HJ, Jo H, Darley-Usmar VM. Nitric oxide-dependent induction of glutathione synthesis through increased expression of $\gamma$-glutamylcysteine synthetase. Arch Biochem Biophys 1998;358:74-82. [PubMed: 9750167]

Moinova HR, Mulcahy RT. An electrophile responsive element (EpRE) regulates $\beta$-naphthoflavone induction of the human $\gamma$-glutamylcsteine synthetase regulatory subunit gene. J Biol Chem 1998;273:14683-14689. [PubMed: 9614065]

Moinova HR, Mulcahy RT. Up-regulation of the human $\gamma$-glutamylcysteine synthetase regulatory subunit gene involves binding of Nrf-2 to an electrophile responsive element. Biochem Biophys Res Commun 1999;261:661-668. [PubMed: 10441483]

Montilla LP, Túnez FI, Muñoz De Agueda MC, Cabrera SE, Motilla MMC, Plascencia AJ, De La Torre LEJ. Protective effect of melatonin against oxidative stress induced by ligature of extra-hepatic biliary duct in rats: comparison with the effect of S-adenosyl-L-methionine. J Pineal Res 2000;28:143-179. [PubMed: 10739300]

Morales A, García-Ruiz C, Miranda M, Marí M, Colell A, Ardite E, Fernández-Checa JC. Tumor necrosis factor increases hepatocellular glutathione by transcriptional regulation of the heavy subunit chain of $\gamma$-glutamylcysteine synthetase. J Biol Chem 1997;272:30371-30379. [PubMed: 9374527]

Morales A, Miranda M, Sanchez-Reyes A, Colell A, Biete A, Fernández-Checa JC. Transcriptional regulation of the heavy subunit chain of $\gamma$-glutamylcysteine synthetase by ionizing radiation. FEBS Lett 1998;427:15-20. [PubMed: 9613591]

Mulcahy RT, Bailey HH, Gipp JJ. Up-regulation of $\gamma$-glutamylcysteine synthetase activity in melphalanresistant human multiple myeloma cells expressing increased glutathione levels. Cancer Chemother Pharmacol 1994a;34:67-71. [PubMed: 7513621]

Mulcahy RT, Bailey HH, Gipp JJ. Transfection of complementary DNAs for the heavy and light subunits of human $\gamma$-glutamylcysteine synthetase results in an elevation of intracellular glutathione and resistance to melphalan. Cancer Res 1995a;55:4771-4775. [PubMed: 7585502]

Mulcahy RT, Gipp JJ. Identification of a putative antioxidant response element in the 5 '-flanking region of the human $\gamma$-glutamylcysteine synthetase heavy subunit gene. Biochem Biophys Res Comm 1995b;209:227-233. [PubMed: 7726839]

Mulcahy RT, Untawale S, Gipp JJ. Transcriptional up-regulation of $\gamma$-glutamylcysteine synthetase gene expression in melphalan-resistant human prostate carcinoma cells. Mol Pharmacol 1994b;46:909_ 914. [PubMed: 7969079]

Mulcahy RT, Wartman MA, Bailey HH, Gipp JJ. Constitutive and $\beta$-naphthoflavone-induced expression of the human $\gamma$-glutamylcysteine synthetase heavy subunit gene is regulated by a distal antioxidant response element/TRE sequence. J Biol Chem 1997;272:7445-7454. [PubMed: 9054446]

Myhrstad MCW, Husberg C, Murphy P, Nordström O, Blomhoff R, Moskaug JØ, Kolstø AB. TCF11/ Nrf1 overexpression increases the intracellular glutathione level and can transactivate the gammaglutamylcysteine synthetase (GCS) heavy subunit promoter. Biochim Biophys Acta 2001;1517:212-219. [PubMed: 11342101]

Nagashima R, Ogita K. Enhanced biosynthesis of glutathione in the spiral ganglion of the cochlea after in vivo treatment with dexamethasone in mice. Brain Res 2006;1117:101-108. [PubMed: 16949561] 
Nakamura S, Kugiyama K, Sugiyama S, Miyamoto S, Koide S, Fukushima H, Honda O, Yoshimura M, Ogawa H. Polymorphism in the 5'-flanking region of human glutamate-cysteine ligase modifier subunit gene is associated with myocardial infarction. Circulation 2002;105:2968-2973. [PubMed: 12081989]

Nakamura S, Sugiyama S, Fujioka D, Kawabata K, Ogawa H, Kugiyama K. Polymorphism in glutamatecysteine ligase modifier subunit gene is associated with impairment of nitric oxide-mediated coronary vasomotor function. Circulation 2003;108:1425-7. [PubMed: 12975258]

Nakamura T, Tomita Y, Ichihara A. Density-dependent growth control of adult rat hepatocytes in primary culture. J Biochem 1983a;94:1029-1035. [PubMed: 6654842]

Nakamura T, Yoshimoto K, Nakayama Y, Tomita Y, Ichihara A. Reciprocal modulation of growth and differentiated functions of mature rat hepatocytes in primary culture by cell-cell contact and cell membranes. Proc Natl Acad Sci, USA 1983b;80:7229-7233. [PubMed: 6580642]

Nefedova Y, Fishman M, Sherman S, Wang X, Beg AA, Gabrilovich DI. Mechanism of all-trans retinoic acid effect on tumor-associated myeloid-derived suppressor cells. Cancer Res 2007;67:1102111028. [PubMed: 18006848]

Németh I, Boda D. Xanthine oxidase activity and blood glutathione redox ration in infants and children with septic shock syndrome. Int Care Med 2001;27:216-221.

Neuschwander-Tetri BA, Nicholson C, Wells LD, Tracy TF Jr. Cholestatic liver injury down-regulates hepatic GSH synthesis. J Surg Res 1996;63:447-451. [PubMed: 8661240]

Oguri T, Fujiwara Y, Isobe T, Katoh O, Watanabe H, Yamakido M. Expression of $\gamma$-glutamylcysteine synthetase ( $\gamma$-GCS) and multidrug resistance-associated protein (MRP), but not human canalicular multispecific organic anion transporter (cMOAT), genes correlates with exposure of human lung cancers to platinum drugs. Br J Cancer 1998;77:1089-1096. [PubMed: 9569044]

Oja SS, Janaky R, Varga V, Saranasaari P. Modulation of glutamate receptor functions by glutathione. Neurochem Int 2000;37:299-306. [PubMed: 10812215]

Ookhtens M, Kaplowitz N. Role of the liver in interorgan homeostasis of glutathione and cyst(e)ine. Sem Liv Dis 1998;18:313-329.

Oppenheimer L, Wellner VP, Griffith OW, Meister A. Glutathione synthetase. Purification from rat kidney and mapping of the substrate binding sites. J Biol Chem 1979;254:5184-90. [PubMed: 447639]

Paolicchi A, Dominici S, Pieri L, Maellaro E, Pompella A. Glutathione catabolism as a signaling mechanism. Biochem Pharmacol 2002;64:1027-35. [PubMed: 12213602]

Paolicchi A, Sotiropuolou M, Perego P, Daubeuf S, Visvikis A, Lorenzini E, Franzini M, Romiti N, Chieli E, Leone R, Apostoli P, Colangelo D, Zunino F, Pompella A. $\gamma$-Glutamyl transpeptidase catalyses the extracellular detoxification of cisplatin in a human cell line derived from the proximal convoluted tubule of the kidney. Eur J Cancer 2003;39:996-1003. [PubMed: 12706370]

Payabvash S, Ghahremani MH, Goliaei A, Mandegary A, Shafaroodi H, Amanlou M, Dehpour AR. Nitric oxide modulates glutathione synthesis during endotoxemia. Free Rad Biol Med 2006;41:18171828. [PubMed: 17157184]

Pompella A, Corti A, Paolicchi A, Giommarelli C, Zunino F. Gamma-glutamyltransferase, redox regulation and cancer drug resistance. Curr Opin Pharmacol 2007;7:360-366. [PubMed: 17613273]

Pompella A, Visvikis A, Paolicchi A, De Tata V, Casini AF. The changing faces of glutathione, a cellular protagonist. Biochem Pharmacol 2003;66:1499-1503. [PubMed: 14555227]

Poot M, Teubert H, Rabinovitch PS, Kavanagh TJ. De novo synthesis of glutathione is required for both entry into and progression through the cell cycle. J Cell Physiol 1995;163:555-560. [PubMed: 7539813]

Rahman I, Smith CA, Antonicelli F, MacNee W. Characterization of $\gamma$-glutamylcysteine synthetaseheavy subunit promoter: a critical role for AP-1. FEBS Lett 1998;427:129-133. [PubMed: 9613613]

Rahman I, Smith CA, Lawson MF, Harrison DJ, MacNee W. Induction of $\gamma$-glutamylcysteine synthetase by cigarette smoke is associated with AP-1 in human alveolar epithelial cells. FEBS Lett 1996;396:21-25. [PubMed: 8906859]

Reber U, Wullner U, Trepel M, Baumgart J, Seyfried J, Klockgether T, Dichgans J, Weller M. Potentiation of treosulfan toxicity by the glutathione-depleting agent buthionine sulfoximine in human malignant glioma cells: the role of Bcl-2. Biochem Pharmacol 1998;55:349-359. [PubMed: 9484802] 
Reyes-Gordillo K, Segovia J, Shibayama M, Vergara P, Moreno MM, Muriel P. Curcumin protects against acute liver damage in the rat by inhibiting $\mathrm{NF}-\kappa \mathrm{B}$, proinflammatory cytokines production and oxidative stress. Biochim Biophys Acta 2007;1770:989-996. [PubMed: 17383825]

Richman PG, Meister A. Regulation of $\gamma$-glutamylcysteine synthetase by nonallosteric feedback inhibition by glutathione. J Biol Chem 1975;250:1422-1426. [PubMed: 1112810]

Seelig GF, Simondsen RP, Meister A. Reversible dissociation of $\gamma$-glutamylcysteine synthetase into two subunits. J Biol Chem 1984;259:9345-9347. [PubMed: 6146611]

Sekhar KR, Long M, Long J, Xu ZQ, Summar ML, Freeman ML. Alteration of transcriptional and posttranscriptional expression of gamma-glutamylcysteine synthetase by diethyl maleate. Radiation Res 1997a;147:592-297. [PubMed: 9146705]

Sekhar KR, Meredith MJ, Kerr LD, Soltaninassab SR, Spitz DR, Xu ZQ, Freeman ML. Expression of glutathione and $\gamma$-glutamylcysteine synthetase mRNA is Jun dependent. Biochem Biophys Res Commun 1997b;234:588-593. [PubMed: 9175757]

Serviddio G, Pereda J, Pallardó FV, Carretero J, Borras C, Cutrin J, Vendemiale G, Poli G, Viña J, Sastre J. Ursodeoxycholic acid protects against secondary biliary cirrhosis in rats by preventing mitochondrial oxidative stress. Hepatoloy 2004;39:711-720.

Shaw JP, Chou I. Elevation of intracellular glutathione content associated with mitogenic stimulation of quiescent fibroblasts. J Cell Physiol 1986;129:193-198. [PubMed: 3771652]

Shi MM, Kugelman A, Iwamoto T, Tian L, Forman HJ. Quinone-induced oxidative stress elevates glutathione and induces $\gamma$-glutamylcysteine synthetase activity in rat lung epithelial L2 cells. J Biol Chem 1994;269:26512-26317. [PubMed: 7929374]

Shi ZZ, Habib GM, Rhead WJ, Gahl WA, He X, Sazer S, Lieberman MW. Mutations in the glutathione synthetase gene cause 5-oxoprolinuria. Nature Genetics 1996;14:361-365. [PubMed: 8896573]

Solis WA, Dalton TP, Dieter MZ, Freshwater S, Harrer JM, He L, Shertzer HG, Nebert DW. Glutamatecysteine ligase modifier subunit: mouse Gclm gene structure and regulation by agents that cause oxidative stress. Biochem Pharmacol 2002;63:1739-1754. [PubMed: 12007577]

Soltaninassab SR, Sekhar KR, Meredith MJ, Freeman ML. Multi-faceted regulation of $\gamma$ glutamylcysteine synthetase. J Cell Physiol 2000;182:163-170. [PubMed: 10623879]

Su GL. Lipopolysaccharides in liver injury: molecular mechanisms of Kupffer cell activation. Am J Physiol Gastrointest Liver Physiol 2002;283:G256-265. [PubMed: 12121871]

Sun S, Zhang H, Xue B, Wu Y, Wang J, Yin Z, Luo L. Protective effect of glutathione against lipopolysaccharide-induced inflammation and mortality in rats. Inflamm Res 2006;55:504-510. [PubMed: 17122969]

Sun WM, Huang ZZ, Lu SC. Regulation of $\gamma$-glutamylcysteine synthetase by protein phosphorylation. Biochem J 1996;320:321-328. [PubMed: 8947504]

Sun Y. Induction of glutathione synthetase by 1,10-phenanthroline. FEBS Lett 1997;408:16-20. [PubMed: 9180259]

Suthanthiran M, Anderson ME, Sharma VK, Meister A. Glutathione regulates activation-dependent DNA synthesis in highly purified normal human T lymphocytes stimulated via the CD2 and CD3 antigens. Proc Natl Acad Sci USA 1990;87:3343-3347. [PubMed: 1970635]

Takada A, Bannai S. Transport of cystine in isolated rat hepatocytes in primary culture. J Biol Chem 1984;259:2441-2445. [PubMed: 6142043]

Tan KP, Yang M, Ito S. Activation of nuclear factor (erythroid-2 like) factor 2 by toxic bile acids provokes adaptive defense responses to enhance cell survival at the emergence of oxidative stress. Mol Pharmacol 2007;72:1380-1390. [PubMed: 17724089]

Tarver H, Schmidt CLA. The conversion of methionine to cystine: Experiments with radioactive sulfur. J Biol Chem 1939;130:67-80.

Thimmulappa RK, Lee H, Rangasamy T, Reddy SP, Yamamoto M, Kensler TW, Biswal S. Nrf2 is a critical regulator of the innate immune response and survival during experimental sepsis. J Clin Invest 2006;116:984-995. [PubMed: 16585964]

Townsend DM, Tew KD, Tapiero H. The importance of glutathione in human disease. Biomed \& Pharmacotherap 2003;57:145-155.

Tsukamoto HC, Lu SC. Current concepts in the pathogenesis of alcoholic liver injury. FASEB J 2001;15:1335-1349. [PubMed: 11387231] 
Urata Y, Honma S, Goto S, Todoroki S, Iida T, Cho S, Honma K, Kondo T. Melatonin induces $\gamma$ glutamylcysteine synthetase mediated by activator protein-1 in human vascular endothelial cells. Free Rad Biol Med 1999;27:838-847. [PubMed: 10515588]

Urata Y, Yamamoto H, Goto S, Tsushima H, Akazawa S, Yamashita S, Nagataki S, Kondo T. Long exposure to high glucose concentration impairs the responsive expression of $\gamma$-glutamylcysteine synthetase by interleukin- $1 \beta$ and tumor necrosis factor- $\alpha$ in mouse endothelial cells. J Biol Chem 1996;271:15146-15152. [PubMed: 8662965]

Vendemiale G, Altomare E, Trizio T, Le Grazie C, Di Padova C, Salerna MT, Carrieri V, Albano O. Effect of oral S-adenosyl-L-methionine on hepatic glutathione in patients with liver disease. Scan J Gastroenterol 1989;24:407-415.

Victor VM, De La Fuente M. Immune cells redox state from mice with endotoxin-induced oxidative stress. Involvement of NF-кB. Free Rad Res 2003;37:19-27.

Walsh AC, Feulner JA, Reilly A. Evidence for functionally significant polymorphism of human glutamate cysteine ligase catalytic subunit: association with glutathione levels and drug resistance in the National Cancer Institute tumor cell line panel. Toxicol Sci 2001;61:218-223. [PubMed: 11353130]

Walters DM, Cho HY, Kleeberger SR. Oxidative stress and antioxidants in the pathogenesis of pulmonary fibrosis: a potential role for Nrf2. Antioxid Redox Signal 2008;10:321-332. [PubMed: 17999635]

Wan YJY, An D, Cai Y, Repa JJ, Chen THP, Flores M, Postic C, Magnuson MA, Chen J, Chien KR, French S, Mangelsdorf DJ, Sucov HM. Hepatocyte-specific mutation establishes retinoid X receptor a as a heterodimeric integrator of multiple physiological processes in the liver. Mol Cell Biol 2000;20:4436-4444. [PubMed: 10825207]

Wang H, Liu H, Liu RM. Gender difference in glutathione metabolism during aging in mice. Exp Gerontology 2003;38:507-517.

Wang W, Chan JY. Nrf1 is targeted to the endoplasmic reticulum membrane by an N-terminal transmembrane domain. J Biol Chem 2006;281:19676-19687. [PubMed: 16687406]

Wild AC, Moinova HR, Mulcahy RT. Regulation of $\gamma$-glutamylcysteine synthetase subunit gene expression by the transcription factor Nrf2. J Biol Chem 1999;274:33627-33636. [PubMed: 10559251]

Woods JS, Davis HA, Baer RP. Enhancement of $\gamma$-glutamylcysteine synthetase mRNA in rat kidney by methyl mercury. Arch Biochem Biophys 1992;296:350-353. [PubMed: 1351382]

Wu Y, Zhang X, Robel RCV, Chen LX, Zeng Y, Aguilo J, Ao Y, Hwang K, French SW, Lu SC, Wan YJY. Retinoid $\mathrm{X}$ receptor $\alpha$ regulates amino acid metabolism, glutathione homeostasis and xenobiotic detoxification processes in mouse liver. Mol Pharmacol 2004;65:550-557. [PubMed: 14978233]

Yamane Y, Furuichi M, Song R, Van NT, Mulcahy RT, Ishikawa T, Kuo MT. Expression of multidrug resistance protein/GS-X pump and $\gamma$-glutamylcysteine synthetase genes is regulated by oxidative stress. J Biol Chem 1998;273:31075-31085. [PubMed: 9813007]

Yan CC, Huxtable RJ. Effects of monocrotaline, a pyrrolizidine alkaloid, on glutathione metabolism in the rat. Biochem Pharmacol 1996;51:375-379. [PubMed: 8573205]

Yan N, Meister A. Amino acid sequence of rat kidney $\gamma$-glutamylcysteine synthetase. J Biol Chem 1990;265:1588-1593. [PubMed: 1967255]

Yang HP, Huang ZZ, Wang JH, Ou XP, Lu SC. Cloning and characterization of the 5'-flanking region of the rat glutamate-cysteine ligase catalytic subunit. Biochem J 2001;357:447-455. [PubMed: 11439094]

Yang HP, Magilnick N, Lee C, Kalmaz D, Ou XP, Chan JY, Lu SC. Nrf1 and Nrf2 regulate rat glutamatecysteine ligase catalytic subunit transcription indirectly via AP-1 and NFkB. Mol Cell Biol 2005a; 25:5933-5946. [PubMed: 15988009]

Yang HP, Magilnick N, Ou XP, Lu SC. Tumor necrosis alpha induces coordinated activation of rat GSH synthetic enzymes via NFkB and AP-1. Biochem J 2005b;391:399-408. [PubMed: 16011481]

Yang HP, Magilnick N, Xia M, Lu SC. Effects of Hepatocyte Growth Factor on Glutathione Synthesis, Growth, and Apoptosis is Cell Density-Dependent. Exp Cell Res 2008;314:398-412. [PubMed: 17950727] 
Yang HP, Zeng Y, Lee TD, Yang T, Ou XP, Chen LX, Haque M, Rippe R, Lu SC. Role of AP-1 in the co-ordinate induction of rat glutamate-cysteine ligase and glutathione synthetase by tertbutylhydroquinone. J Biol Chem 2002;277:35232-35239. [PubMed: 12093805]

Yang SQ, Lin HZ, Lane MD, Clemens M, Diehl AM. Obesity increases sensitivity to endotoxin liver injury: implications for the pathogenesis of steatohepatitis. Proc Natl Acad Sci USA 1997;94:255762. [PubMed: 9122234]

Yang Y, Dieter MZ, Chen Y, Shertzer HG, Nebert DW, Dalton TP. Initial characterization of the glutamate-cysteine ligase modifier subunit Gclm (-l-) knockout mouse: novel model system for a severely compromised oxidative stress response. J Biol Chem 2002;277:49446-49452. [PubMed: 12384496]

Yao KS, Godwin AK, Johnson SW, Ozols RF, O’Dwyer PJ, Hamilton TC. Evidence for altered regulation of $\gamma$-glutamylcysteine synthetase gene expression among cisplatin-sensitive and cisplatin-resistant human ovarian cancer cell lines. Cancer Res 1995;55:4367-4374. [PubMed: 7671249]

Yoshida K, Hirokawa J, Tagami S, Kawakami Y, Urata Y, Kondo T. Weakened cellular scavenging activity against oxidative stress in diabetes mellitus: regulation of glutathione synthesis and efflux. Diabetologia 1995;38:201-210. [PubMed: 7713315]

Zarnegar R, Michalopoulos GK. The many faces of hepatocyte growth factor: From hepatopoiesis to hematopoiesis. J Cell Biol 1995;129:1177-1180. [PubMed: 7775566]

Zhang C, Walker LM, Hinson JA, Mayeux PR. Oxidant stress in rat liver after lipopolysaccharide administration: effect of inducible nitric-oxide synthase inhibition. J Pharmacol Exp Therap 2000;293:968-972. [PubMed: 10869399]

Zhang H, Court N, Forman HJ. Submicromolar concentrations of 4-hydroxynonenal induce glutamate cysteine ligase expression in HBE1 cells. Redox Report 2007;12:101-106. [PubMed: 17263920]

Zhang H, Liu H, Dickinson DA, Liu RM, Postlethwait EM, Laperche Y, Forman HJ. $\gamma$-Glutamyl transpeptidase is induced by 4-hydroxynonenal via EpRE/Nrf2 signaling in rat epithelial type II cells. Free Rad Biol Med 2006;40:1281-1292. [PubMed: 16631518]

Zheng S, Yumei F, Chen A. De novo synthesis of glutathione is a prerequisite for curcumin to inhibit hepatic stellate cell (HSC) activation. Free Rad Biol Med 2007;43:444-453. [PubMed: 17602960] 


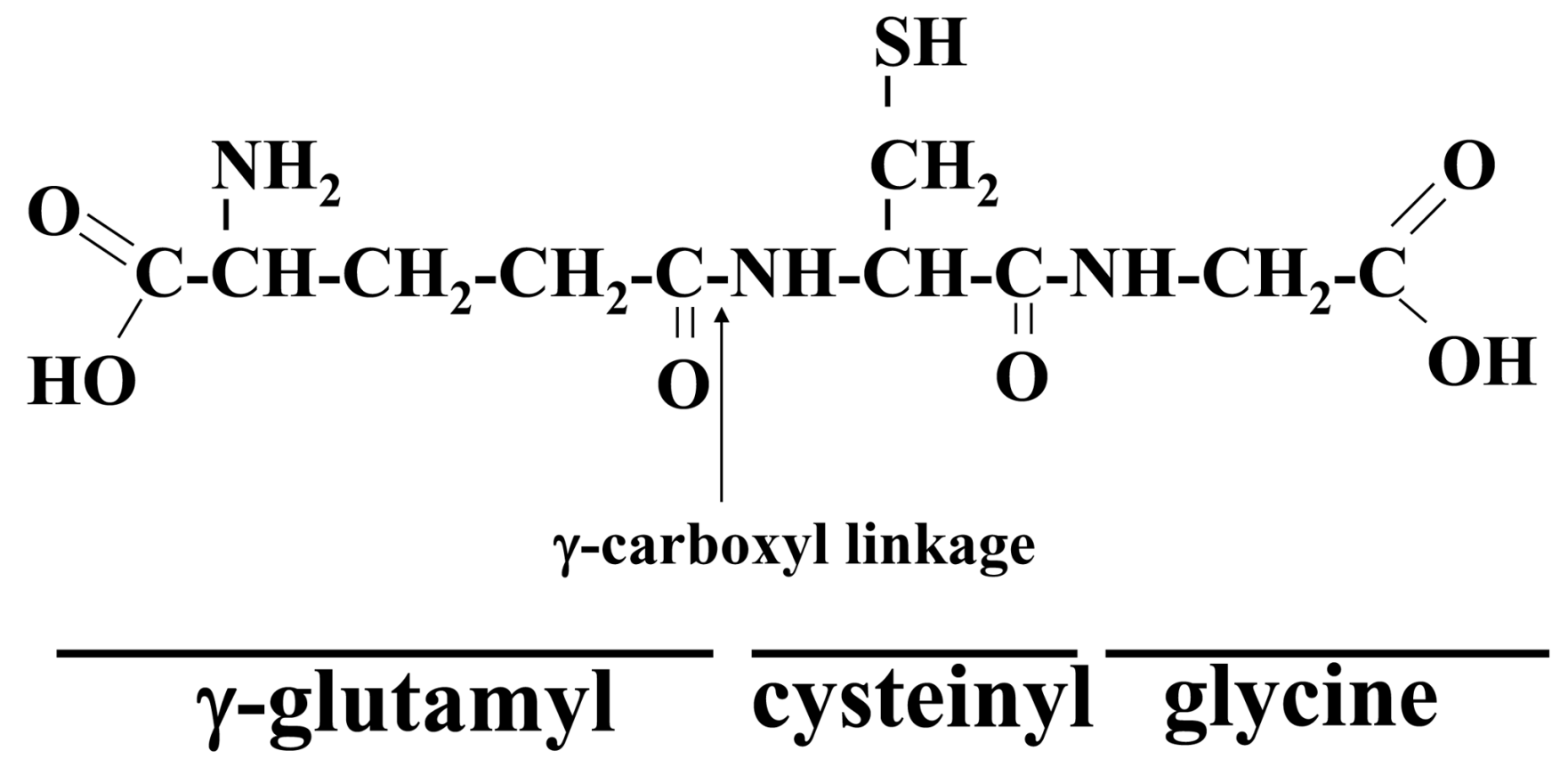

Fig. 1.

Structure of GSH or $\gamma$-glutamylcysteinyl glycine, where the N-terminal glutamate and cysteine are linked by the $\gamma$-carboxyl group of glutamate. 

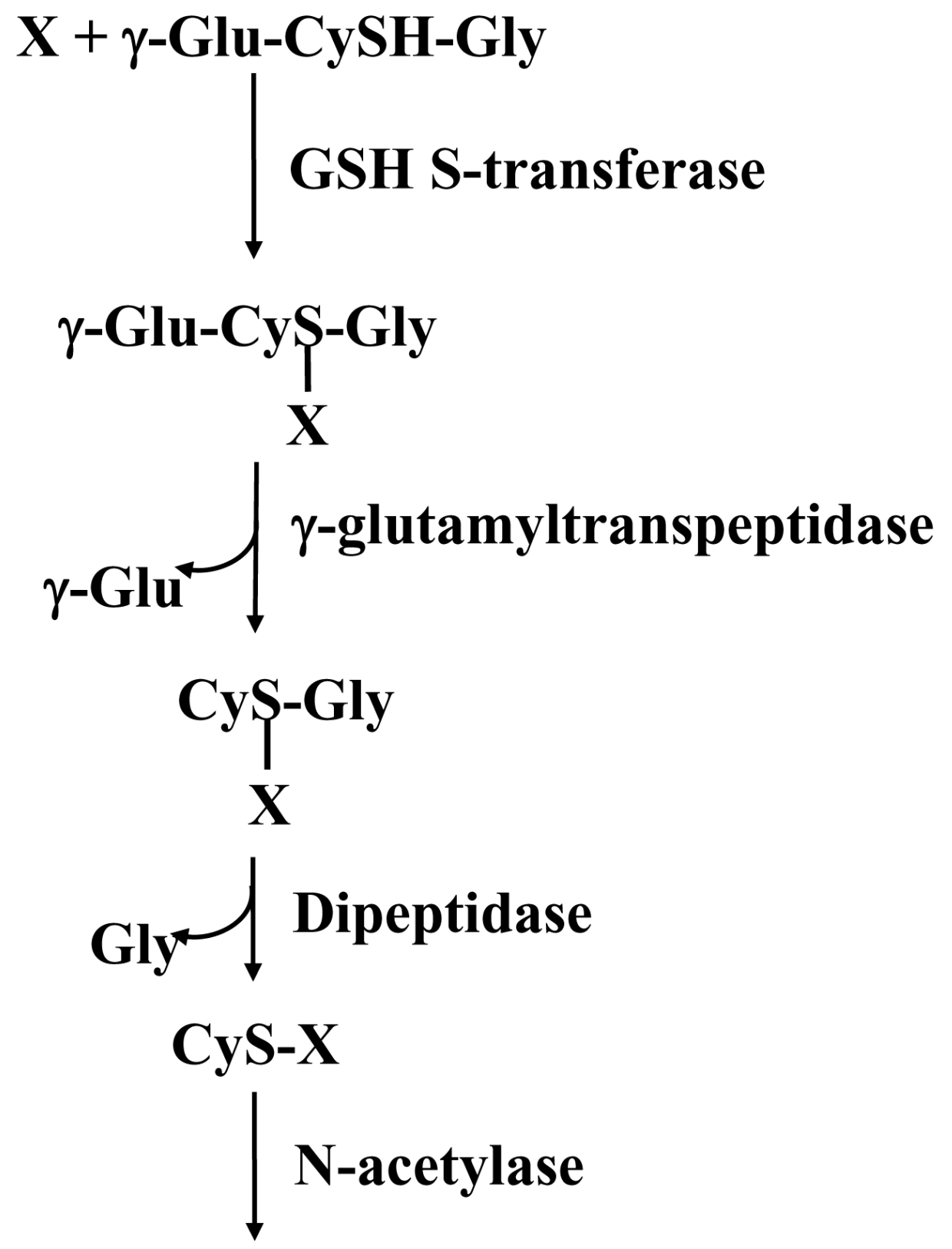

\section{N-acetyl-Cys-X (mercapturic acid)}

Fig. 2.

Detoxifying action of GSH through the mercapturic pathway. X is a compound with an electrophilic center that can form GSH conjugate in a reaction catalyzed by GSH S-transferase. The $\gamma$-glutamyl moiety is then cleaved by $\gamma$-glutamyltranspeptidase, releasing the cysteinylglycine conjugate. This is further broken down by dipeptidase, resulting in the formation of the cysteinyl conjugate. This is followed by $\mathrm{N}$-acetylation of the cysteine conjugate catalyzed by $\mathrm{N}$-acetylase, forming a mercapturic acid. 


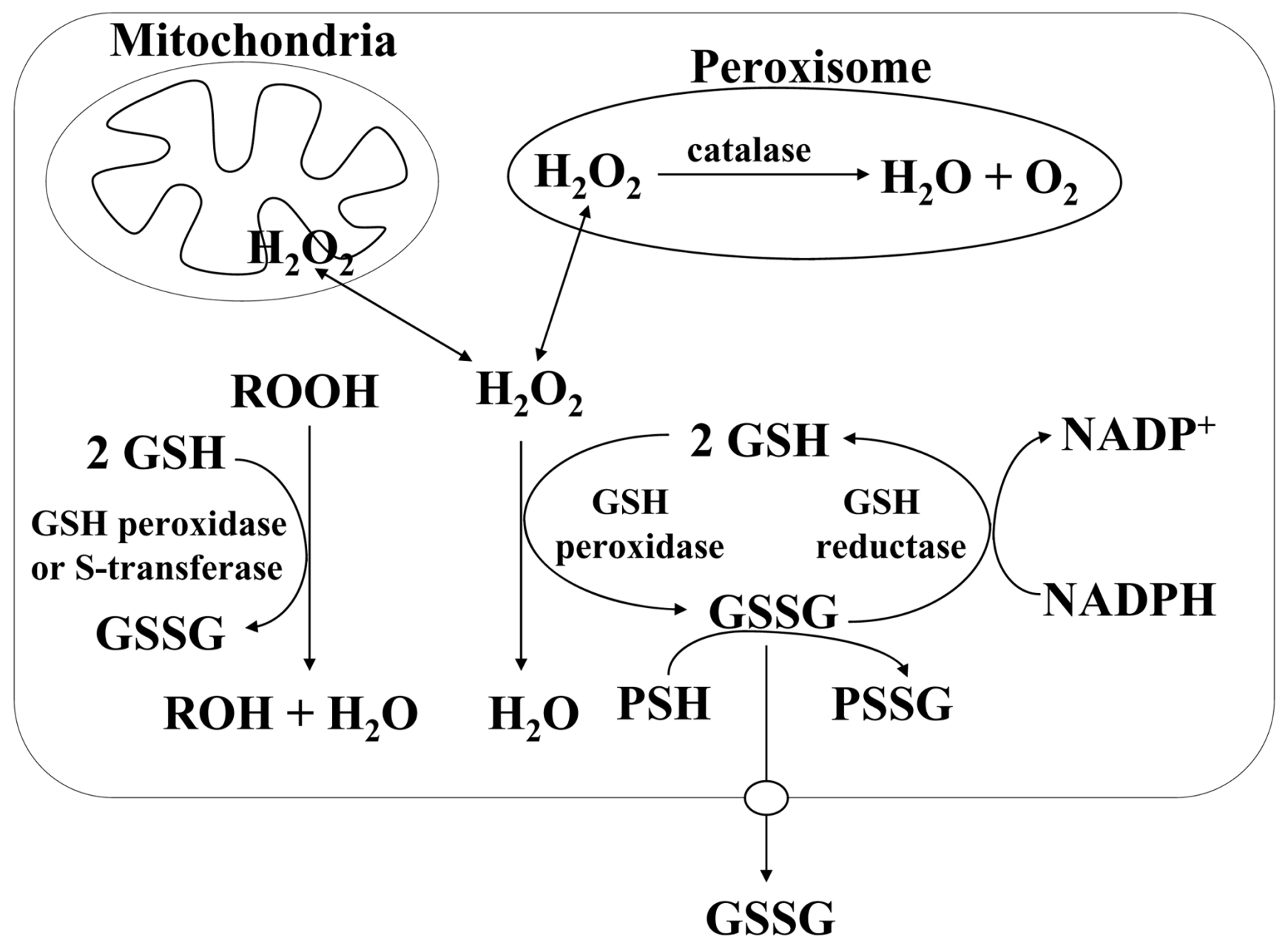

Fig. 3.

GSH is an important antioxidant. Hydrogen peroxide, generated as a result of aerobic metabolism, can be metabolized by GSH peroxidase in the cytosol and mitochondria, and by catalase in the peroxisome. GSSG that is formed is reduced back to GSH by GSSG reductase at the expense of NADPH, thereby forming a redox cycle. Organic peroxides (ROOH) can be reduced by either GSH peroxidase or GSH S-transferase. Under severe oxidative stress, the ability of the cell to reduce GSSG to GSH may be overcome, leading to an accumulation of GSSG. To avoid a shift in the redox equilibrium, GSSG can either be actively transported out of the cell or react with a protein sulfhydryl (PSH) to form a mixed disulfide (PSSG). 


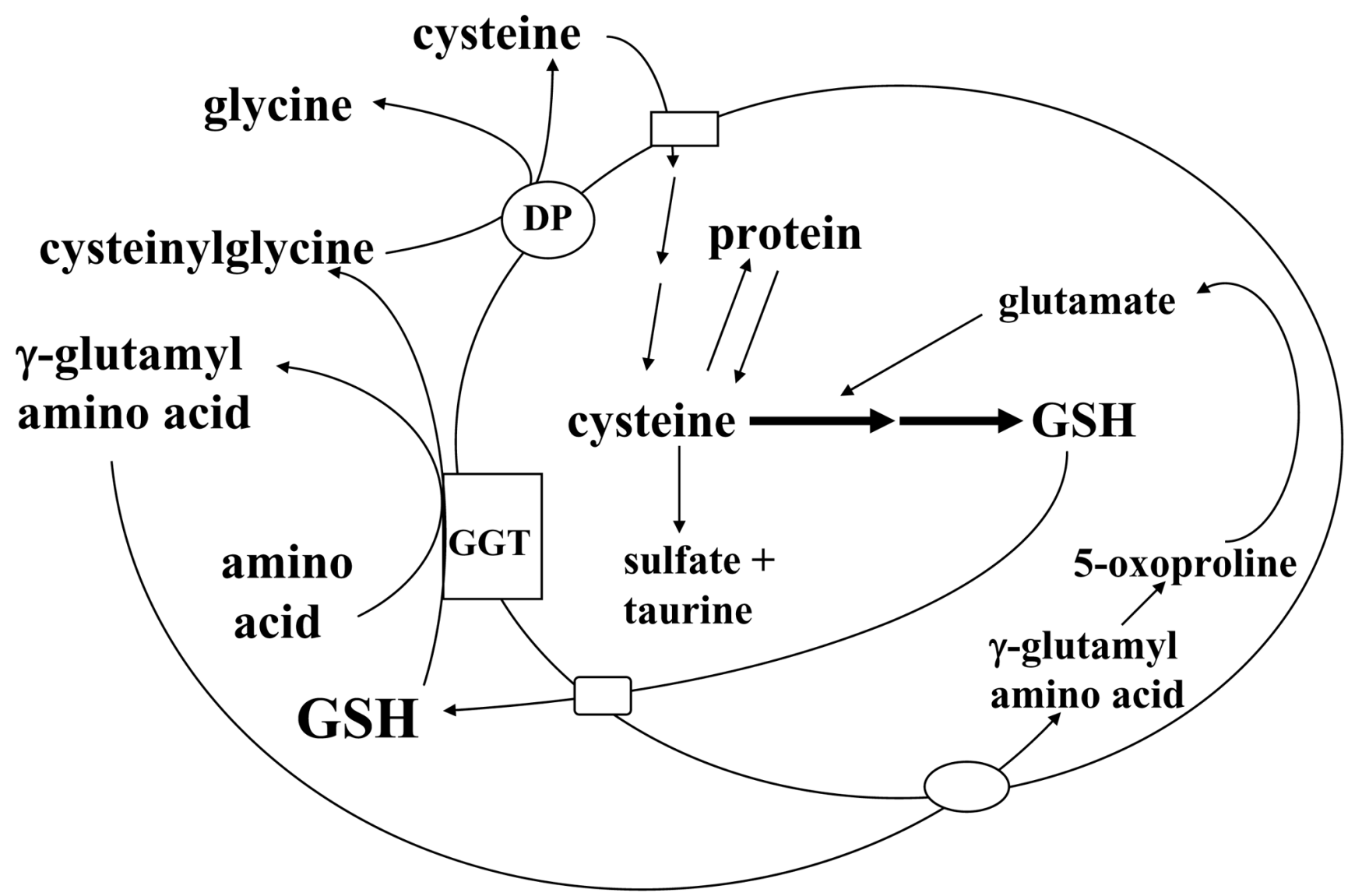

Fig. 4.

GSH as cysteine storage via the $\gamma$-glutamyl cycle. The $\gamma$-glutamyl cycle utilize GSH as a continuous source of cysteine. Cysteine is taken up readily by most cells and once it enters the cell, most of it is incorporated into GSH while the rest is incorporated into newly synthesized proteins and/or broken down into sulfate and taurine. GSH is exported from the cell and the ecto-enzyme GGT then transfers the $\gamma$-glutamyl moiety of GSH to an amino acid (the best acceptor being cystine), forming $\gamma$-glutamyl amino acid and cysteinylglycine. The $\gamma$-glutamyl amino acid can then be transported back into the cell to complete the cycle. Once inside the cell, the $\gamma$-glutamyl amino acid can be further metabolized to release the amino acid and 5oxoproline, which can be converted to glutamate. Cysteinylglycine is broken down by dipeptidase (DP) to generate cysteine and glycine, which are then transported back into the cell to be reincorporated into GSH. 


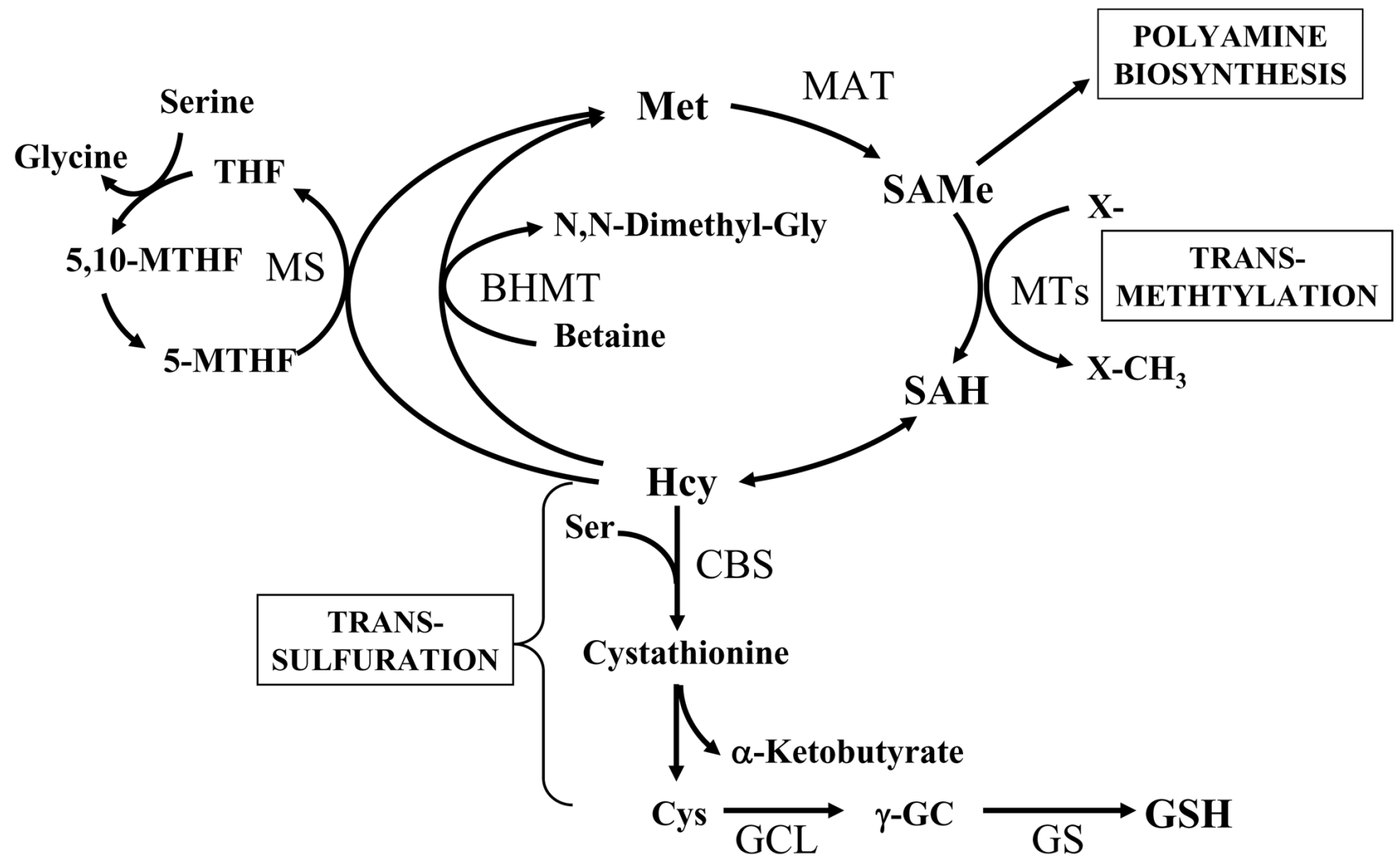

Fig. 5.

Hepatic methionine metabolism and GSH synthesis. Up to half of the daily intake of methionine (Met) is catabolized to S-adenosylmethionine (SAMe) in the liver in a reaction catalyzed by methionine adenosyltransferase (MAT). SAMe is the link to three key metabolic pathways polyamine synthesis, transmethylation and transsulfuration. Polyamine synthesis is required for cell growth and here SAMe is decarboxylated and the remaining propylamino moiety is donated to putrescine and spermidine. In transmethylation, SAMe donates its methyl group to a large variety of acceptor molecules in reactions catalyzed by methyltransferases (MTs). Sadenosylhomocysteine (SAH), generated as a result of transmethylation, is a potent inhibitor of all transmethylation reactions. Hydrolysis of SAH to homocysteine (Hcy) and adenosine is through a reversible reaction catalyzed by SAH hydrolase, whose thermodynamics favors biosynthesis rather than hydrolysis. In vivo this reaction proceeds as hydrolysis because the products Hcy and adenosine are promptly removed. Hcy can be remethylated to form methionine via methionine synthase (MS), which requires folate and vitamin $\mathrm{B}_{12}$ and betaine homocysteine methyltransferase (BHMT), which requires betaine. MS-mediated homocysteine remethylation requires 5-methyltetrahydrofolate (5-MTHF), which is generated from 5,10 -methylenetetrahydrofolate $(5,10-\mathrm{MTHF})$ in a reaction catalyzed by methylenetetrahydrofolate reductase. 5-MTHF is then converted to tetrahydrofolate (THF) as it donates its methyl group and THF is converted back to 5,10-MTHF. In trans-sulfuration, Hcy is converted to cysteine (Cys), the rate-limiting precursor for GSH, via a two-step enzymatic process catalyzed by cystathionine $\beta$-synthase (CBS) and cystathionase, both requiring vitamin $\mathrm{B}_{6}$. Cys is then converted to GSH. The trans-sulfuration pathway is particularly active in the liver and allows methionine and SAMe to be effectively utilized as GSH precursor. 